\title{
Comparison of SAM-Based Junctions with Ga203/ EGaln Top Electrodes to Other Large-Area Tunneling Junctions
}

\section{Citation}

Nijhuis, Christian A., William F. Reus, Jabulani R. Barber, and George M. Whitesides. 2012. Comparison of SAM-Based Junctions with Ga203/EGaln Top Electrodes to Other Large-Area Tunneling Junctions. Journal of Physical Chemistry C 116, no. 26: 14139-14150.

\section{Published Version}

doi:10.1021/jp303072a

\section{Permanent link}

http://nrs.harvard.edu/urn-3:HUL.InstRepos:11928053

\section{Terms of Use}

This article was downloaded from Harvard University's DASH repository, and is made available under the terms and conditions applicable to Open Access Policy Articles, as set forth at http:// nrs.harvard.edu/urn-3:HUL.InstRepos:dash.current.terms-of-use\#OAP

\section{Share Your Story}

The Harvard community has made this article openly available.

Please share how this access benefits you. Submit a story.

\section{Accessibility}




\title{
Comparison of SAM-Based Junctions with $\mathrm{Ga}_{2} \mathrm{O}_{3} / \mathrm{EGaIn}$ Top-
}

\section{Electrodes to other Large-Area Tunneling Junctions}

Christian A. Nijhuis, ${ }^{1,2}$ William F. Reus, ${ }^{2}$ Jabulani R. Barber, ${ }^{2}$ and George M.

Whitesides ${ }^{2,3 *}$

${ }^{1}$ Department of Chemistry, National University of Singapore, 3 Science Drive 3, Singapore 117543.

${ }^{2}$ Department of Chemistry and Chemical Biology, Harvard University, 12 Oxford St, Cambridge, MA 02138, USA.

${ }^{3}$ Kalvi Institute of Bionano Science \& Technology, Harvard University, 29 Oxford Street, Cambridge, MA 02138, USA

corresponding author:

Tel.: 6174589430

Fax.: 6174589857

e-mail: gwhitesides@gmwgroup.harvard.edu

Key words: molecular electronics, self-assembled monolayers, charge transport, tunneling junctions, SAMs

\begin{abstract}
This paper compares the $J(V)$ characteristics obtained for self-assembled monolayer (SAM)-based tunneling junctions with top-electrodes of the liquid eutectic of gallium and indium (EGaIn) fabricated using two different procedures: i) stabilizing the
\end{abstract}


EGaIn electrode in PDMS microchannels, and ii) suspending the EGaIn from the tip of a syringe. These two geometries of the EGaIn electrode (with, at least when in contact with air, its solid $\mathrm{Ga}_{2} \mathrm{O}_{3}$ surface film), produce indistinguishable data. The junctions incorporated SAMs of $\mathrm{SC}_{\mathrm{n}-1} \mathrm{CH}_{3}$ (with $\mathrm{n}=12,14,16$, or 18) supported on ultra-flat, template-stripped silver electrodes. Both methods generated high yields of junctions (70 $85 \%)$ that were stable enough to conduct measurements of $J(\mathrm{~V})$ with statistically large numbers of data $(\mathrm{N}=400-1000)$. The devices with the top-electrode stabilized in microchannels also made it possible to conduct measurements of $J(\mathrm{~V})$ as a function of temperature, almost down to liquid nitrogen temperatures $(T=110-293 \mathrm{~K})$. The $J(V)$ characteristics were independent of $T$, and linear in the low-bias regime (-0.10 to $1.0 \mathrm{~V}$ ); the current density decreased exponentially with increasing thickness of the SAM. These observations indicate that tunneling is the main mechanism of charge transport across these junctions. Both methods gave values of the tunneling decay coefficient, $\beta$, of $\sim 1.0$ $\mathrm{n}_{\mathrm{c}}^{-1}\left(\sim 0.80 \mathrm{~A}^{-1}\right)$, and the pre-exponential factor, $J_{0}$ (which is a constant that includes contact resistance), of $\sim 3.0 \times 10^{2} \mathrm{~A} / \mathrm{cm}^{2}$. Comparison of the electrical characteristics of the junctions generated using EGaIn by both methods against the results of other systems for measuring charge transport indicated that the value of $\beta$ generated using EGaIn electrodes is compatible with the consensus of values reported in the literature. While there is no consensus for the value of $J_{0}$, the value of $J_{0}$ estimated using the $\mathrm{Ga}_{2} \mathrm{O}_{3} / \mathrm{EGaIn}$ electrode is compatible with other values reported in the literature. The agreement of experimental values of $\beta$ across a number of experimental platforms provides strong evidence that the structures of the SAMs - including their molecular and supramolecular structure, and their interface with the two electrodes - dominate charge transport in both 
types of EGaIn junctions. These results establish that studies of $J(V)$ characteristics of $\mathrm{Ag}^{\mathrm{TS}}$-SAM// $\mathrm{Ga}_{2} \mathrm{O}_{3} / \mathrm{EGaIn}$ junctions are dominated by the structure of the organic component of the SAM, and not by artifacts due to the electrodes, the resistance of the $\mathrm{Ga}_{2} \mathrm{O}_{3}$ surface film, or to the work functions of the metals.

\section{Introduction}

This paper compares the electrical characteristics obtained for two types of tunneling junctions, both comprising template-stripped silver bottom electrodes $\left(\mathrm{Ag}^{\mathrm{TS}}\right)$, self-assembled monolayers (SAMs), with top-electrodes of a liquid eutectic alloy of indium and gallium (EGaIn); in one junction, the EGaIn is stabilized in microchannels; ${ }^{1}$ in the second, it is suspended as a drop with a cone-shaped tip from a syringe: ${ }^{2}$ the paper also compares these electrical measurements to those obtained with other types of socalled "large-area tunneling junctions" (e.g., junctions that contain SAMs rather than single molecules ${ }^{3}$ ). EGaIn has composition $75.5 \%$ Ga and $24.5 \%$ In by weight, and its reported melting point is $15.7^{\circ} \mathrm{C} ;{ }^{4}$ when exposed to air, its surface spontaneously and rapidly forms a thin film of $\mathrm{Ga}_{2} \mathrm{O}_{3}$. We discuss - using both previously published data ${ }^{1,2}$ and new data - the electrical characteristics of junctions incorporating $\mathrm{Ga}_{2} \mathrm{O}_{3} / \mathrm{EGaIn}$ in terms of current density, $J\left(\mathrm{~A} / \mathrm{cm}^{2}\right)$, as a function of voltage, $V(\mathrm{~V})$, and the tunneling

decay constant, $\beta\left(\mathrm{n}_{\mathrm{c}}{ }^{-1}\right.$, or per $\left.\mathrm{CH}_{2}\right)$, and $J_{0}\left(\mathrm{~A} / \mathrm{cm}^{2}\right)$, which is a constant that includes properties of the interfaces (see below). Fitting the values of $J$ (at a particular potential), plotted as a function of length of the $\mathrm{SAMs}$ of $\mathrm{SC}_{\mathrm{n}-1} \mathrm{CH}_{3}$ (over the range of $\mathrm{n}=12,14,16$, 18 ), to the Simmons equation (see below) yielded values of $\beta$ and $J_{0}$. 
We also compare the values of $J, J_{0}$, and $\beta$ obtained in this work with values reported in the literature for other systems (see below), to try to identify consensus values for $\beta$ (and perhaps for $J_{0}$ ), and to determine the reliability of our methods for constructing SAM-based junctions. These results are important in establishing the validity of $\mathrm{Ga}_{2} \mathrm{O}_{3} / \mathrm{EGaIn}$-based junctions in physical-organic studies of charge transport across these junctions. $^{5,6,7}$

\section{Background}

Tunneling. The mechanism of charge transport across SAM-based junctions with SAMs of $n$-alkanethiolates is believed to be coherent tunneling, ${ }^{8,9,10}$ and hole tunneling is theoretically more favorable than electron tunneling. ${ }^{11}$ The potential barrier is defined by the molecular and electronic structure of the molecules, the collective supramolecular structure of the SAM, and the properties of the interfaces between the SAM and the electrodes. The rate of tunneling decreases exponentially with the width of the barrier, is independent of temperature, and is usually approximated (with unknown accuracy and little detailed theoretical justification) by a form of the Simmons equation (eq. 1), where $J_{0}\left(\mathrm{~A} / \mathrm{cm}^{2}\right)$ is a constant that depends on the system and includes contact resistance, $d(\AA)$ is the width of the tunneling barrier, and $\beta\left(n_{\mathrm{C}}{ }^{-1}\right.$, or $\left.\AA^{-1}\right)$ is the decay constant. ${ }^{12,13}$

$$
J=J_{0} e^{-\beta d}=J_{0} 10^{-0.4343 \beta d}
$$

Tunneling through a SAM is more probable than through space $\left(\beta=2.9 \AA^{-1}\right.$ for a vacuum gap between two metals with work functions of $5 \mathrm{eV}$; values of $\beta=0.80 \AA^{-1}$, or $1.0 n_{\mathrm{C}^{-1}}$, have often been observed for SAMs of n-alkanethiolates on gold, silver, or mercury). ${ }^{8} \mathrm{~A}$ generally accepted mechanism to explain the difference between values of $\beta$ in 
"insulating" media, and in vacuum, is super-exchange tunneling. ${ }^{14}$ Interactions of the electrons with the orbitals of the organic molecules in the SAM increase the probability of tunneling, and make "through-bond" tunneling more probable than "through-space" tunneling. ${ }^{15}$

\section{Junctions with Top-Electrodes of $\mathrm{Ga}_{2} \mathrm{O}_{3} / \mathrm{EGaIn}$ Suspended from a Syringe.}

We are developing junctions with $\mathrm{Ga}_{2} \mathrm{O}_{3} / \mathrm{EGaIn}$ as a top-electrode material. ${ }^{1,2,16-21}$ In these junctions, a thin layer of $\mathrm{Ga}_{2} \mathrm{O}_{3}$ that forms spontaneously on the EGaIn serves as a protective layer that prevents the bulk Ga and In from penetrating, and perhaps alloying with, the bottom-electrode. These junctions are less prone to short-circuiting than junctions using $\mathrm{Hg}$ as a top-electrode, and thus offer i) higher yields (> $80 \%$ and in some cases $100 \%{ }^{16}$ ) of working junctions in most cases than other top-electrodes, ii) greater ease of manipulation, and iii) more rapid collection of data. Also, $\mathrm{Ga}_{2} \mathrm{O}_{3} / \mathrm{EGaIn}$ has the advantage over $\mathrm{Hg}$ that it is non-volatile and non-toxic. This system is, however, one that requires an experienced operator, and in which there is significant "art" involved in the experiments (easily taught in the laboratory but not yet easily and completely described in writing in a paper). Also, these junctions - with the cone-shaped tip of $\mathrm{Ga}_{2} \mathrm{O}_{3} / \mathrm{EGaIn}$ suspended from a syringe - do not allow measurements of $J(\mathrm{~V})$ as a function of temperature over a broad range of temperatures.

\section{Junctions with Top-Electrodes of $\mathrm{Ga}_{2} \mathrm{O}_{3} / \mathrm{EGaIn}$ Stabilized in Micro-}

Channels. To avoid (at least some of) the limitations of the junctions with cone-shaped tips of $\mathrm{Ga}_{2} \mathrm{O}_{3} / \mathrm{EGaIn}$ suspended from a syringe, we fabricated silver micro-electrodes supporting SAMs, positioned microchannels molded in polydimethylsiloxane (PDMS) over these micro-electrodes, and filled the microchannels with EGaIn (probably having a 
thin or patchy discontinuous layer of $\mathrm{Ga}_{2} \mathrm{O}_{3}$ between the EGaIn and the SAMs). ${ }^{1} \mathrm{We}$ successfully fabricated junctions of n-alkanethiolates over molecular lengths for $\mathrm{Ag}^{\mathrm{TS}}-\mathrm{SC}_{\mathrm{n}-1} \mathrm{CH}_{3} / / \mathrm{Ga}_{2} \mathrm{O}_{3} / \mathrm{EGaIn}$ of $\mathrm{n}=12,14,16$, or $18 .{ }^{1}$ This method i) makes it possible to conduct measurement of $J(\mathrm{~V})$ as a function of temperature, $T(\mathrm{~K})$, over the range of $T$ $=110-293 \mathrm{~K}$, ii) produces a packaged device that can be transported without destroying the contact between the electrodes and the molecules, and iii) mitigates some of the variability that affects junctions formed with conical tips of $\mathrm{Ga}_{2} \mathrm{O}_{3} / \mathrm{EGaIn}$, by providing reproducible conditions under which to form contacts between the electrodes and the SAM with well-defined areas. This method also has the potential to generate structures that might eventually be incorporated into practically useful devices, although the current generation of devices has limited stability (on the order of 2-3 days; see below). This method has one disadvantage compared to cone-shaped tips of $\mathrm{Ga}_{2} \mathrm{O}_{3} / \mathrm{EGaIn}$ : it requires basic cleanroom procedures to fabricate the electrodes and the molds for the PDMS, while all of the fabrication steps of the method using suspended conical tips of $\mathrm{Ga}_{2} \mathrm{O}_{3} / \mathrm{EGaIn}$ can be performed in the laboratory.

These two methods, however, stand together, in contrast to other techniques (See Supplemental Information for more details), in that they do not require i) the deposition of metal or other reactive species on SAMs (a process associated with damage to the $\mathrm{SAMs}^{22,23,24}$ ), ii) a solvent bath and two face-to-face SAMs (as in Hg-drop based junctions), ${ }^{25}$ or iii) a buffer layer of conducting polymer, formed using solvents and annealing steps that are poorly understood, and with poorly understood electrical properties. ${ }^{26}$ Importantly, both methods involving $\mathrm{Ga}_{2} \mathrm{O}_{3} /$ EGaIn enable the collection of 
statistically large numbers of data, and make it possible to perform careful statistical analysis of charge transport as a function of the structure of the SAM.

These two methods also share disadvantages: they feature an incompletely characterized layer of $\mathrm{Ga}_{2} \mathrm{O}_{3}$ between the SAM and the bulk EGaIn, an ill-defined interface between the SAM and the $\mathrm{Ga}_{2} \mathrm{O}_{3}$, and an uncertainty in the effective electrical contact area of the $\mathrm{Ga}_{2} \mathrm{O}_{3} / \mathrm{EGaIn}$ electrode with the SAM. (There are "ill-defined interfaces" in all junctions now being used, so the $\mathrm{Ga}_{2} \mathrm{O}_{3} / \mathrm{EGaIn}$ system is not exceptional in this regard.) For SAMs of $\mathrm{SC}_{\mathrm{n}-1} \mathrm{CH}_{3}$, the values of $\beta$ and $J_{0}$ determined using these methods are statistically indistinguishable, even though we strongly suspect that the details of the contact of the $\mathrm{Ga}_{2} \mathrm{O}_{3} / \mathrm{EGaIn}$ with the SAM, and the composition of the layer of the $\mathrm{Ga}_{2} \mathrm{O}_{3}$ differs significantly between them (see below). This observation is important: it is one of several that we use to conclude that the layer of $\mathrm{Ga}_{2} \mathrm{O}_{3}$ is conductive enough that its influence on measurements of $J(\mathrm{~V})$ is not significant (see below).

Characteristics of the Layer of $\mathrm{Ga}_{2} \mathrm{O}_{3}$. We discussed many of the characteristics of the layer of $\mathrm{Ga}_{2} \mathrm{O}_{3}$ in previous papers. ${ }^{1,16,18,20}$, We found, ${ }^{20}$ as have other groups ${ }^{27,28}$, that this self-limiting film of predominantly $\mathrm{Ga}_{2} \mathrm{O}_{3}$ is $\sim 0.7 \mathrm{~nm}$ thick. The layer of $\mathrm{Ga}_{2} \mathrm{O}_{3}$ may be no more than 65 - 100 times more resistive than the bulk EGaIn (determined using two different techniques ${ }^{1,16}$ ); EGaIn, in turn, has a resistivity close to that of $\mathrm{Ag}$. We conclude that the layer of $\mathrm{Ga}_{2} \mathrm{O}_{3}$ is sufficiently conductive that it does not influence the $J(\mathrm{~V})$ characteristics of SAM-based tunneling junctions that use top-electrodes of $\mathrm{Ga}_{2} \mathrm{O}_{3} / \mathrm{EGaIn}$. We also found that the mechanism of charge transport across this thin layer of $\mathrm{Ga}_{2} \mathrm{O}_{3}$ appeared to proceed by a thermally activated process, ${ }^{1}$ and not by 
tunneling. This finding is in agreement with observations of Paterson et al., ${ }^{29}$ who reported that thermionic emission is the dominant mechanism of charge-transport through epitaxially grown films of $\mathrm{Ga}_{2} \mathrm{O}_{3}$ on GaAs. Thus, the $\mathrm{Ga}_{2} \mathrm{O}_{3}$ does not provide an electrically significant tunneling barrier in series with the barrier defined by the SAMs.

We measured the composition of the layer of $\mathrm{Ga}_{2} \mathrm{O}_{3}$ on a drop of EGaIn (we will describe the details in a separate paper $^{20}$ ), and its thickness, by time-of-flight secondaryion mass spectroscopy (ToF SIMS) and angle-resolved X-ray photoelectron spectroscopy (ARXPS). We concluded that the layer of $\mathrm{Ga}_{2} \mathrm{O}_{3}$ consists mainly of $\mathrm{Ga}_{2} \mathrm{O}_{3}$ (with low concentrations of indium, indium oxides, and other gallium oxides). These measurements also indicated that for the cone-shaped tips of $\mathrm{Ga}_{2} \mathrm{O}_{3} / \mathrm{EGaIn}$, the layer of $\mathrm{Ga}_{2} \mathrm{O}_{3}$ is not homogenous: this layer -as it forms- has a thickness of $\sim 0.7 \mathrm{~nm}$. It is flexible but incompressible and during mechanical deformation during tip formation, and or contact with the SAM, it buckles and forms local grains or lumps of gallium oxides with diameters of $\sim 1 \mu \mathrm{m}$; these particles penetrate into the bulk EGaIn by up to $\sim 1 \mu \mathrm{m}$.

Possible Defects inside $\mathrm{Ag}^{\mathrm{TS}}$-SAM//Ga $2 \mathrm{O}_{3} /$ EGaIn Junctions. We have previously described the two classes of possible defects, which we called "thin-area" and “thick-area" defects, in SAM-based junctions. ${ }^{30}$ Thin-area defects result in smaller values of $d$ than expected for the thickness of the SAM; these defects, in turn, cause larger values for $J$ than expected (eq. 1). ${ }^{30}$ We identified five possible sources that cause disorder in the SAMs leading to thin area defects: ${ }^{31}$ i) the metal-bottom electrode has grain boundaries, ${ }^{32}$ ii) the bottom-electrode has step-edges (vacancy islands cause similar defects), ${ }^{32}$ iii) physisorbed impurities on the bottom-electrode or impurities present in the electrode material may locally prevent the adsorption of the alkanethiols, ${ }^{31}$ iv) the SAM 
has a tilt angle and, therefore, domain boundaries where the top-electrode may partially penetrate the SAM, ${ }^{33}$ and v) at the edges of the electrodes the SAM cannot pack densely, and, thus, will have defects (see below). ${ }^{34}$

Defects that cause a larger-than-ideal separation between the two electrodes will cause low current densities (eq. 1). ${ }^{30}$ We call such defects "thick area" defects. We expect the two main sources of thick area-defects to be non-conformal contact of the topelectrode with the SAM, and physisorbed impurities on top of the SAM or top-electrode. We believe that the $\mathrm{Ga}_{2} \mathrm{O}_{3} / \mathrm{EGaIn}$ top-electrode makes electrical contact with the SAM only over a fraction ( 20-50\%) of the estimated "footprint" of contact. Scanning electron micrographs (SEM) and optical micrographs indicate that the layer $\mathrm{Ga}_{2} \mathrm{O}_{3}$ is rough. Only a part of the tip of the cone-shaped $\mathrm{Ga}_{2} \mathrm{O}_{3} / \mathrm{EGaIn}$ is in conformal contact with the SAMs, and this percentage may vary from contact to contact; the area of electrical contact is also not established quantitatively (see Supplemental Information Fig. S4). ${ }^{1}$ The uncertainties due to the variation in the area of contact are probably small - for most junctions, and in the hands of a careful experimentalist - relative to other sources of variation. ${ }^{30}$ Further, so long as the area of contact is relatively constant from junction to junction, it is not important in physical-organic studies, which depend on relative values of $J$ as a function of the structure of the SAM, and not on absolute values of $J$.

The Properties of $\mathrm{Ga}_{2} \mathrm{O}_{3} / \mathbf{E G a I n}$ Inside Microchannels. We believe that a layer of $\mathrm{Ga}_{2} \mathrm{O}_{3}$ is responsible for the fact that $\mathrm{Ga}_{2} \mathrm{O}_{3} / E G a I n$ behaves like an elastic material until it experiences a critical surface stress $(\sim 0.5 \mathrm{~N} / \mathrm{m})$; at this value of stress, it yields (probably by fracturing under tension or shear, and by buckling under compression) and flows readily. ${ }^{35,36}$ This property makes it possible for $\mathrm{Ga}_{2} \mathrm{O}_{3} / \mathrm{EGaIn}$ to fill microchannels 
rapidly when sufficient vacuum is applied to the outlet of the channel. Because the $\mathrm{Ga}_{2} \mathrm{O}_{3}$ skin adheres well to oxidized PDMS, structures formed by flowing $\mathrm{Ga}_{2} \mathrm{O}_{3} / \mathrm{EGaIn}$ through microchannels of oxidized PDMS remain stable, even when ambient pressure is restored.

In a previous report on this system, we suggested that the layer of $\mathrm{Ga}_{2} \mathrm{O}_{3}$ at the $\mathrm{SAM} / / \mathrm{Ga}_{2} \mathrm{O}_{3}$ interface might be discontinuous - bulk EGaIn might form direct contact with the SAMs - because the microchannels do not contain enough $\mathrm{O}_{2}$ to react with all exposed Ga surface atoms while EGaIn is filling the channel. ${ }^{1}$ We now believe that the layer of $\mathrm{Ga}_{2} \mathrm{O}_{3}$ between bulk EGaIn and oxidized PDMS is continuous, although possibly variable in thickness, because $\mathrm{O}_{2}$ can diffuse through the PDMS.

We did not try to fabricate our devices under an atmosphere of $\mathrm{N}_{2}$ since, in the absence of $\mathrm{O}_{2}$, the EGaIn top-electrodes do not form stable, continuous structures in the microchannels in oxidized PDMS.

\section{Results and Discussion}

General Characteristics of the Devices. We have described the procedure for the fabrication of arrays of SAM-based junctions using microchannels, with topelectrodes of $\mathrm{Ga}_{2} \mathrm{O}_{3} / \mathrm{EGaIn} .{ }^{1}$ The preparation of the $\mathrm{Ag}^{\mathrm{TS}}$-electrodes requires photolithography, but the silver electrodes can be produced in large numbers (we produced 12 devices - that is 84 junctions - per four-inch wafer). It is, thus, possible to fabricate large numbers of devices - each containing multiple junctions, and incorporating a different type of SAM - from one round of photolithography.

The devices are stable to handling in the lab, and unperturbed (in our experiments) by normal vibrations in the apparatus and variations in the ambient temperature. 
Applying pressure to the PDMS, or subjecting it to large shocks, resulted in shorting of the devices, leakage of the $\mathrm{Ga}_{2} \mathrm{O}_{3} / \mathrm{EGaIn}$ out of the channels, and/or separation of the layer of PDMS from the substrate. Thus, the interaction of the PDMS and the substrate is stable enough for everyday handling in the lab, but not for rough handling.

The mechanical stability of the devices, and the convenience with which large numbers of devices can be formed, makes it possible to perform interpretable physicalorganic studies (we discuss statistical issues in the following section). This mechanical stability also makes it possible to use these devices to perform measurements of $J(\mathrm{~V})$ as function of temperature, $T .{ }^{1}$ In the process of varying the temperature of the junctions from $295 \mathrm{~K}$ to $110 \mathrm{~K}$, the differences between the thermal expansion coefficients for PDMS $\left(3 \times 10^{-4} \mathrm{~K}^{-1}\right),{ }^{37}$ glass $\left(0.08 \times 10^{-4} \mathrm{~K}^{-1}\right),{ }^{38} \mathrm{Ga}_{2} \mathrm{O}_{3}\left(0.042 \times 10^{-4} \mathrm{~K}^{-1}\right),{ }^{39} \mathrm{Ag}(0.18 \times$ $\left.10^{-4} \mathrm{~K}^{-1}\right),{ }^{40}$ and EGaIn $\left(1.1 \times 10^{-4} \mathrm{~K}^{-1}\right)^{41}$ did not cause shorts, lead to loss of contact, or alter the device characteristics in destructive ways. We observed, as we contacted the drop of $\mathrm{Ga}_{2} \mathrm{O}_{3} / \mathrm{EGaIn}$ with the micro-needles of the probe station at different temperatures, that the bulk EGaIn solidified at $T=240-260 \mathrm{~K}$. (This temperature is lower than the melting point reported in literature: $T=288 \mathrm{~K}) .{ }^{19}$ We performed our temperature-dependent measurements of $J(\mathrm{~V})$ in vacuum $\left(1 \times 10^{-6} \mathrm{bar}\right)$. Lowering the pressure did not lead to short or open circuits, nor did it modify the $J(\mathrm{~V})$ characteristics observed at room temperature (the only temperature for which comparisons between pressures was possible, due to the nature of the apparatus).

Electrical Characterization of the Junctions. We used this system to collect $J(\mathrm{~V})$ data for junctions incorporating $\mathrm{SAMs}$ of $\mathrm{S}\left(\mathrm{CH}_{2}\right)_{\mathrm{n}-1} \mathrm{CH}_{3}(\mathrm{n}=12,14,16$, or 18; hereafter abbreviated $\mathrm{SC}_{\mathrm{n}-1} \mathrm{CH}_{3}$ ); these data were reported previously. ${ }^{1}$ We choose this 
set of n-alkanethiolates explicitly to allow comparisons with data collected using other systems, and to assist in comparing different protocols. With these data, we determined the reproducibility and the yield of working devices (in the Supporting Information, Table S1 summarizes the number of devices, junctions, and yields in working junctions). We did not include devices that were short-circuits or open-circuits: we attributed failures of this type to errors in the fabrication process, rather than defects in the junction. Thus, the yields we reported reflect the characteristics of the junction, rather than the skill of the user in fabricating the electrodes and assembling the junction.

We analyzed the data statistically to determine the mean of the log of the current density, $\langle\log \mid J\rangle\left(\mathrm{A} / \mathrm{cm}^{2}\right)$, and the values of the tunneling decay constant, $\beta$, and preexponential factor, $J_{0}\left(\mathrm{~A} / \mathrm{cm}^{2}\right)$, using a procedure described in previous publications. ${ }^{1,2}$ Briefly, we constructed histograms of the values of $|J|$. We observed, and assumed, that the values of $J$ were approximately log-normally distributed, and characterized by the $\log$-mean $\langle J\rangle_{\log }$. Plotting the values of $|J|$ on a log-scale, thus, produced normal distributions of $\log (|J|)$ to which we fitted Gaussian curves by non-linear least-squares fitting to all data (including shorts or open circuits) from devices that produced at least one working junction. Including outliers has the potential to distort calculations of the means, but we minimized this error through the collection of large numbers of data. The fitting parameters of each Gaussian gave the log-mean, $\langle\log |J|>$, and the log-standard deviation, $\sigma_{\log }$, of $\log |J|$ which we used, in turn, to construct the plots of $\langle|J|>$ as a function of $V$ (Fig. 1).

We determined the values of $\beta$ (see below) with four data: $\langle\log |J|\rangle$ for the four different $\mathrm{n}$-alkanethiolates. The error of the value of $\beta$ is also determined by the error of 
each value of $\langle\log |J|>$ which has been determined using hundreds of data. Because we used large numbers of data, our confidence levels of the values of $\beta$ are $>95 \%$ (see, for details, reference 2 ). We could only improve the accuracy of the value of $\beta$ by measuring more n-alkanethiolates of different lengths, or by reducing the log-standard deviation of the values of $\langle\log |J|>$. The number of n-alkanethiolates that are available and give SAMs of reasonably well understood structures is limited, and we have described our efforts in reducing the log-standard deviation of $\langle\log |J|\rangle$ before by improving the top-electrode material, ${ }^{1,2,16-19}$ the roughness of the bottom-electrodes ${ }^{30}$ (see section background), and purity of the n-alkanethiolates. $^{2}$

Stability of the Junctions. The stability of the cross-bar devices over time is crucial for conducting physical and physical-organic studies. We tested the stability of 12 working $\mathrm{Ag}^{\mathrm{TS}}-\mathrm{SC}_{17} \mathrm{CH}_{3} / / \mathrm{Ga}_{2} \mathrm{O}_{3} / \mathrm{EGaIn}$ junctions after standing for 48 hours, undisturbed, under ambient conditions at room temperature. All 12 junctions worked (see Table S1 in the Supporting Information) - that is, they did not short, or give unstable results - after this period of time. Figure 2 shows the $J(\mathrm{~V})$-characteristics at $t=0 \mathrm{~h}$ and at $t=48 \mathrm{~h}$ after assembly of the devices. The $J(\mathrm{~V})$ characteristics look similar, but the current density through these junctions decreased by approximately a factor of five. One junction of the type $\mathrm{Ag}^{\mathrm{TS}}-\mathrm{SC}_{11} \mathrm{CH}_{3} / / \mathrm{Ga}_{2} \mathrm{O}_{3} / \mathrm{EGaIn}$ showed a decrease of the current density of a factor of $2.0 \times 10^{2}$ over the course of 13 days (see Supplemental Information). To minimize the influence of aging of the devices, we measured $J(\mathrm{~V})$ within two to four hours after completing the fabrication of the devices.

We do not know the reason for the observed decrease in current density. One possibility is the formation of a layer of silver oxide or silver sulfide at the surface of the 
Figure 1: Plots of $\langle\log (|J|)\rangle$ vs. $V$, and histograms of $\log (|J|)$ at $-0.50 \mathrm{~V}$ and $-0.20 \mathrm{~V}$ (with Gaussian fits) for junctions incorporating $\mathrm{SAMs}$ of $\mathrm{SC}_{11} \mathrm{CH}_{3}(\mathrm{~A}, \mathrm{~B}$, and $\mathrm{C}$ ), $\mathrm{SC}_{15} \mathrm{CH}_{3}(\mathrm{D}, \mathrm{E}$, and $\mathrm{F}), \mathrm{SC}_{14} \mathrm{CH}_{3}\left(\mathrm{G}, \mathrm{H}\right.$, and I), and $\mathrm{SC}_{17} \mathrm{CH}_{3}(\mathrm{~J}, \mathrm{~K}$, and $\mathrm{L}) . N_{|J|}$ indicates the total number of measured values of current density plotted in the histogram. The data for junctions with $\mathrm{SAMs}$ of $\mathrm{SC}_{11} \mathrm{CH}_{3}$ or $\mathrm{SC}_{17} \mathrm{CH}_{3} \mathrm{SAM}$ have been reproduced by two researchers. These data are taken from reference 1. 

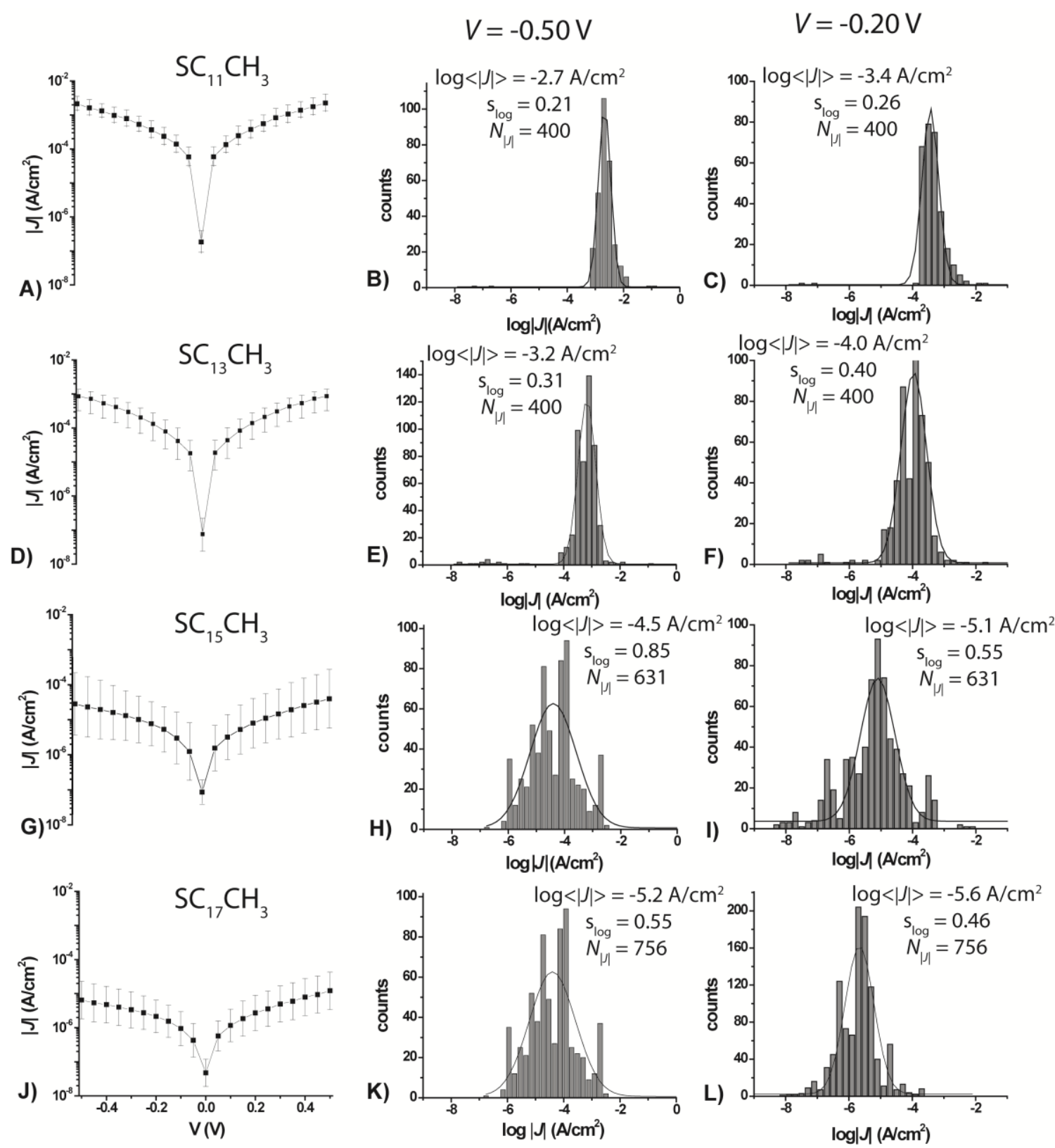
Figure 2: Plot of $\langle\log (|J|)\rangle$ vs. $V$ for $\mathrm{Ag}^{\mathrm{TS}}-\mathrm{SC}_{17} \mathrm{CH}_{3} / / \mathrm{Ga}_{2} \mathrm{O}_{3} / \mathrm{EGaIn}$ cross-bar devices measured at $t=0$ and at $t=48 \mathrm{~h}$. Each point corresponds to the mean of the Gaussian function fitted to the histograms of $\log (|J|)$ (Fig. 1) and the error bars represent one standard deviation of the Gaussian function above and below the mean. The values of $J$ obtained at $t=0$ are one-fifth of those obtained at $t=48 \mathrm{~h}$. 


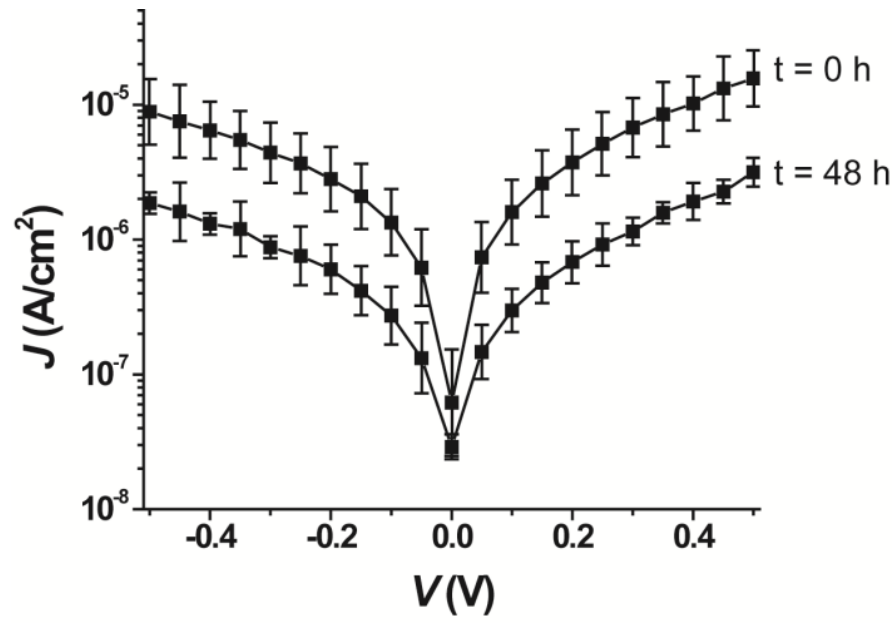


substrate another one is reaction of $\mathrm{RS}-\mathrm{Ag}$ with atmospheric $\mathrm{O}_{2}$ to form $\mathrm{RSO}_{3}{ }^{-} \mathrm{Ag}^{+}$or other oxidized sulfur species. ${ }^{33,42}$

Dependence of $\boldsymbol{J}$ on Temperature. We have measured the $J(\mathrm{~V})$ curves of the $\mathrm{Ag}^{\mathrm{TS}}-\mathrm{SC}_{13} \mathrm{CH}_{3} / / \mathrm{Ga}_{2} \mathrm{O}_{3} / \mathrm{EGaIn}$ cross-bar junctions in vacuum $\left(\sim 1 \times 10^{-6}\right.$ bar $)$ over the range of temperatures of $110-293 \mathrm{~K} .{ }^{1}$ The $J(\mathrm{~V})$ curves are (nearly) independent of $T$ over this range of temperatures. The $J(\mathrm{~V})$ curves are linear in the low-bias regime $(-0.10$ to $0.10 \mathrm{~V}) .{ }^{1}$ These two observations are consistent with coherent tunneling as the dominant mechanism of charge transport in the $\mathrm{Ag}^{\mathrm{TS}}-\mathrm{SC}_{13} \mathrm{CH}_{3} / / \mathrm{Ga}_{2} \mathrm{O}_{3} / \mathrm{EGaIn}$ junctions. ${ }^{10,12,13,14}$ Figure 3 shows the Arrhenius plots for two devices: one with a SAM of $\mathrm{SC}_{17} \mathrm{CH}_{3}$ and the other with a $\mathrm{SAM}$ of $\mathrm{SC}_{13} \mathrm{CH}_{3}$. These Arrhenius plots show that the junctions with $\mathrm{SAMs}$ of $\mathrm{SC}_{17} \mathrm{CH}_{3}$ have a small contribution from some thermally activated process. During this measurement, the current density appeared to decrease from $4.9 \mu \mathrm{A} / \mathrm{cm}^{2}$ at $T=270 \mathrm{~K}$, to $3.7 \mu \mathrm{A} / \mathrm{cm}^{2}$ at $T=130 \mathrm{~K}$. We can not guarantee that this change in $J(\sim 25 \%)$ is not an artifact (that is, not due to some cause other than a change in $J$ due to a thermally activated contribution to charge transport). From the slope of the Arrhenius plots, we determined the activation energy, $E_{\mathrm{a}}$, using eq. 4 , where the Boltzmann constant $k_{\mathrm{B}}=8.62 \times 10^{-5} \mathrm{eV} \mathrm{K}^{-1}$.

$$
J=J_{0} \exp \left(-E_{a} / k_{B} T\right)
$$

We estimated that $E_{\mathrm{a}}=10 \pm 2.1 \mathrm{meV}\left(R^{2}=0.98\right)$ for junctions with $\mathrm{SAMs}$ of $\mathrm{SC}_{17} \mathrm{CH}_{3}$. For junctions with $\mathrm{SAMs}$ of $\mathrm{SC}_{13} \mathrm{CH}_{3}$, the value of $E_{\mathrm{a}}$ was $2.5 \pm 1.5 \mathrm{meV}$, but the noise in the data is so large $\left(R^{2}=0.21\right)$ that this value is probably not meaningful.

We do not know what causes the small, but probably real, thermally activated component of charge transport across the $\mathrm{SC}_{17} \mathrm{CH}_{3}$ junctions, but it might in principle 
Figure 3: Arrhenius plots for a junction with a $\mathrm{SAM}$ of $\mathrm{SC}_{13} \mathrm{CH}_{3}$ in the temperature range of $160-270 \mathrm{~K}(\mathrm{~A})$ and for a junction with a $\mathrm{SAM}$ of $\mathrm{SC}_{17} \mathrm{CH}_{3}$ in the temperature range of $130-270 \mathrm{~K}(\mathrm{~B})$. Values of $J$ were measured at $+0.50 \mathrm{~V}$ and $\mathrm{R}^{2}$ is the coefficient of determination obtained by linear regression of the data. 


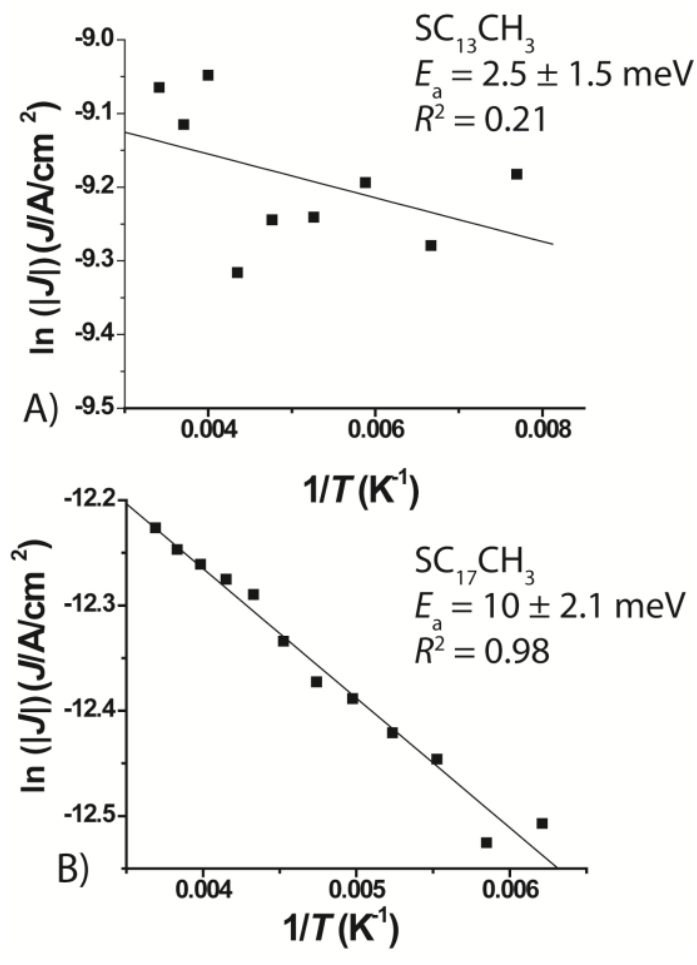


involve: i) charge transport through the layer of $\mathrm{Ga}_{2} \mathrm{O}_{3}$, ii) conformational changes of the molecules inside the junctions, ${ }^{43,44}$ or iii) charge transport mediated by impurities. ${ }^{45} \mathrm{We}$ believe that charge transport through the layer of $\mathrm{Ga}_{2} \mathrm{O}_{3}$ is an unlikely contributor, because we have measured temperature-dependent charge transport through the layer of $\mathrm{Ga}_{2} \mathrm{O}_{3}$ in the absence of a SAM, and found that the activation energy for this system depends strongly on the applied bias; ${ }^{1}$ the conductivity of this layer is also four orders of magnitude higher than that of a SAM of $\mathrm{SC}_{10} \mathrm{CH}_{3} .{ }^{16}$ By contrast, in the SAM-based junctions reported here, we observe no dependence of $E_{a}$ on applied bias; this observation indicates that even the minor, thermally activated charge transport in these junctions proceeds by a different mechanism than that observed in the $\mathrm{Ga}_{2} \mathrm{O}_{3}$ layer. Furthermore, the fact that $E_{a}$ differs for SAMs of different length suggests that the thermally activated charge transport we observe is (at least partially) due to the molecular structure of the SAM, and is not an effect of the electrodes alone.

\section{The Values of $\beta$ and $J_{0}$ of Junctions with Top-electrodes of $\mathrm{Ga}_{2} \mathrm{O}_{3} / \mathrm{EGaIn}$}

Stabilized in Microchannels. We measured $J$ for four lengths of n-alkanethiolates to determine how charge transport depends on the thickness, $d\left(n_{\mathrm{C}}\right.$, or $\AA$ ), of the SAMs in the junctions. Figure 4A shows the average current density, $\langle|J|\rangle\left(\mathrm{A} / \mathrm{cm}^{2}\right)$, as a function of $n_{\mathrm{C}}$ at $V=0.050,0.10,0.20,0.30,0.40$, and $0.50 \mathrm{~V}$ : the values of $\langle|J|\rangle$ decrease exponentially with increasing $n_{\mathrm{C}}$. This observation is consistent with the Simmons equation, which describes tunneling across an insulator, and indicates that the mechanism of charge transport in our junctions is predominantly tunneling.

The Value of $\boldsymbol{\beta}$ Depends on the Voltage. We fitted the data of $\left\langle|J|>\right.$ vs. $n_{\mathrm{C}}$ to eq. 1 (substituting $n_{\mathrm{C}}$ for $d$ ) at several values of $V$ to determine the values of $\beta$ and $J_{0}$ (Figure 
Figure 4: A) $|J|$ as a function of the number of carbon atoms in the alkyl chain measured over a range of applied bias, from $V=-0.050$ to $-0.5 \mathrm{~V}$. Each point corresponds to the mean of the Gaussian function fitted to the histograms of $\log (|J|)$ (Fig. 1) and the error bars represent one standard deviation of the Gaussian function. The lines are fits of eq. $\mathbf{1}$ to the data (the fitting results are listed in Table 1). B) The value $\beta$ as a function of the applied bias. 


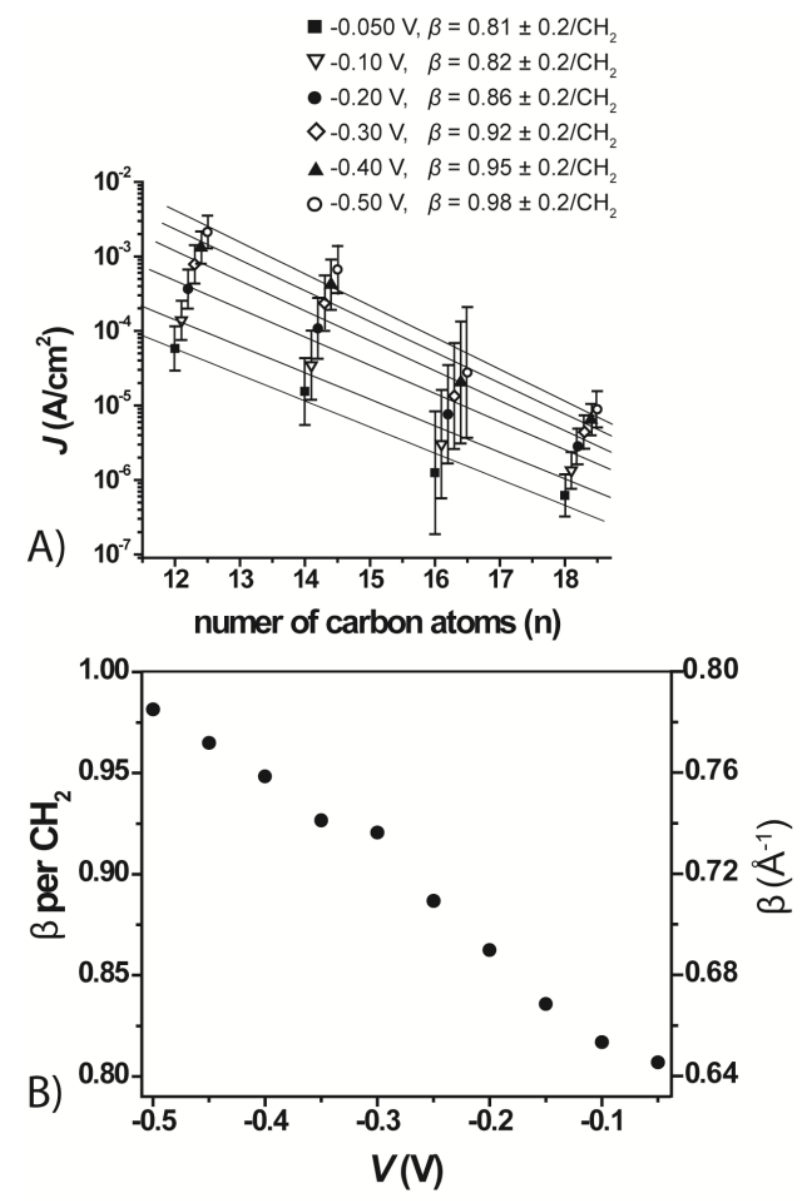


Table 1: Fitting Results ${ }^{\mathrm{a}}$ to Plots of the Value of $J$ as a Function of the Number of Carbon Atoms in the SAM.

\begin{tabular}{lll}
\hline Applied bias $(\mathbf{V})^{\mathbf{b}}$ & $\boldsymbol{\beta} \AA^{-1}$ & $\boldsymbol{J}_{\mathbf{0}} \mathbf{( A / \mathbf { c m } ^ { 2 } )}$ \\
\hline-0.050 & 0.81 & 0.93 \\
-0.10 & 0.81 & 2.48 \\
-0.15 & 0.84 & 5.6 \\
-0.20 & 0.86 & 13 \\
-0.25 & 0.89 & 25 \\
-0.30 & 0.92 & 57 \\
-0.35 & 0.93 & 79 \\
-0.40 & 0.95 & $1.4 \times 10^{2}$ \\
-0.45 & 0.96 & $2.2 \times 10^{2}$ \\
-0.50 & 0.98 & $3.4 \times 10^{2}$ \\
\hline
\end{tabular}

${ }^{\text {a }}$ These fitting results were obtained by fitting eq. 1 to the plots shown in Figure 10.

${ }^{\mathrm{b}}$ These values represent all applied biases in the range of 0.050 to $0.50 \mathrm{~V}$. 
4A). Table 1 lists the values of $\beta$ and $J_{0}$ in the potential range from -0.050 to $-0.50 \mathrm{~V}$. We found that the value of $\beta$ increases with increasing magnitude of applied bias; Figure 4B shows this dependence of the value of $\beta$ on the applied bias (see below for a discussion of this dependence). We do not understand the details of how $\beta$ depends on the potential. Despite the large error in determining the value of $\beta$, each value determined at a different bias is statistically significantly different from the others. The large number of data in these analyses greatly improves the sensitivity of the t-tests. ${ }^{21}$ The full form of the Simmons equation predicts a decrease of the value of the decay constant, $\beta$, with increasing magnitude of bias, ${ }^{12,13}$ but we observe the opposite trend: the value of $\beta$ increases with increasing magnitude of bias. This trend has also been observed by us (using cone-shaped tips of $\mathrm{Ga}_{2} \mathrm{O}_{3} / \mathrm{EGaIn}$ ), and by others. ${ }^{46,47,59}$ This result is interesting, but not, per se, troublesome at this point in the study of rates tunneling of charges across SAMs for two reasons: i) the Simmons equation is a very approximate treatment of tunneling in these molecular systems; in the absence of a detailed quantum mechanical theory to guide analysis, and particularly one that takes into account the atomic-and molecular-level structures of the SAMs, there is no reason to be concerned about deviations from it. ii) The applied voltage corresponds to a very large electric field gradients across the SAM $\left(10^{7}-10^{9} \mathrm{~V} / \mathrm{m}\right)$; changes in these voltages could cause changes in thickness (through electrostriction), orientation (as a result of anisotropic polarizability) or contact resistance (especially at the $\mathrm{CH}_{3} / / \mathrm{Ga}_{2} \mathrm{O}_{3}$ interface) that are not considered in the Simmons equation. Thus, at the very least, the observed behavior suggests that there is a limit to how accurately the Simmons model alone can describe these junctions. To explain the dependence of $\beta$ on applied bias, Frisbie et al ${ }^{59}$ Majda et 
al., ${ }^{48}$ and $\mathrm{we}^{12}$ have previously suggested an explanation based on electrostriction, but the range of possible reasons for deviation from the Simmons model is large.

Consensus Values of $\boldsymbol{\beta}$ and of $\boldsymbol{J}_{\mathbf{0}}$. An important unresolved issue is that, while there exists a consensus across a wide range of systems and techniques that the value of $\beta$ near $V= \pm 0.5 \mathrm{~V}$ is approximately $\beta=0.70-0.90 \AA^{-1}$, or $0.875-1.125 n_{\mathrm{C}}^{-1}$, there is little consensus concerning $J_{0}$. Currently, there is no way to determine $J_{0}$ without using a longrange extrapolation that is prone to large error; there is also no reason to believe that $J_{0}$ should, necessarily be the same for different junctions, since their interfacial structures may be quite different. Despite the large uncertainty in $J_{0}$, and the use of a simple form of the Simmons equation with all of its inherent limitations and assumptions, $J_{0}$ is still a potentially useful parameter for making comparisons among SAM-based tunneling junctions. $J_{0}$ may carry information about the efficiency of charge transport across the interfaces between the electrodes and the SAMs, the resistivity or resistances of the interfaces between SAM and the electrode, the density of states available for tunneling through the SAM, and the influence of artifacts (such as metal filaments) on a particular experiment.

Table 2 shows the values of $J_{0}$ and $\beta$ for several types of SAM-based tunneling junctions and Figure 5 shows the same values of $\beta$ as function of $J_{0}$. Table 2 includes data obtained for large-area junctions and does not contain data obtained with conductive probe AFM based techniques, ${ }^{8,47,49,50}$ break junctions,,${ }^{51,52}$ or $\mathrm{STM},{ }^{53}$ based techniques. We refer to a comprehensive review reported by others for a broader comparison across different test beds. ${ }^{3}$ AFM, STM, and break junction techniques yield statistically large numbers of data, but measure only a small collection of molecules, or even single 
molecules, while the techniques listed in Table 2 measure areas of SAMs containing up to $10^{12}$ molecules. Scanning probe-based techniques give values of $\beta=\sim 0.80 \AA^{-1}$, (or $\left.\sim 1.0 n_{\mathrm{C}}{ }^{-1}\right) ;{ }^{49-53}$ this value helps to consolidate the consensus value of $\beta$, but the experimental details of these two classes of methods are so different that meaningful comparisons of $J_{0}$ are difficult, if not impossible.

Figure 9 is just a method of displaying data; there is no reason to expect a functional dependency of $\beta$ on $J_{0}$. Figure 9 shows that the values of $J_{0}($ at $V=0.50 \mathrm{~V})$ obtained with various systems and techniques vary by more than eight orders of magnitude, but the range of $10-10^{3} \mathrm{~A} / \mathrm{cm}^{2}$ contains half of the values of $J_{0}$, representing four different approaches to contacting the SAM (Au-SAM//polymer/Hg, AgSAM//SAM-Hg, and Ag-SAM// $\mathrm{Ga}_{2} \mathrm{O}_{3} / \mathrm{EGaIn}$ junctions, the latter encompassing both conical tips and microfluidic arrays). We believe that this range of $J_{0}$ is representative for junctions of the form metal-SAM//(protective layer)liquid-metal. Junctions of the form metal-SAM $/ /$ (protective layer)/metal and metal-SAM $/ /$ metal exhibit values of $J_{0}$ that are larger $\left(10^{5}-10^{9} \mathrm{~A} / \mathrm{cm}^{2}\right)$. This large range suggests that charge transport across SAMelectrode interfaces may differ substantially among these three classes of junctions.

The junctions in Table 2 and Figure 5 can be divided into two groups: those with a protective layer (a polymer, an oxide film, or a second SAM) between the SAM and the top-electrode, and those without a protective layer. Junctions with a protective layer (except for the Ag-SAM//SAM-Hg junctions reported in reference 54) give a relatively narrow range of values of $J_{0}$, from $10^{2}-10^{3} \mathrm{~A} / \mathrm{cm}^{2}$. Junctions without a protective layer give values of $J_{0}$ that are higher, and more widely spread, than those with a protective layer. Thus, we refer to the values of $\beta=0.70-0.90 \AA^{-1}$, or $0.875-1.125 n_{C}^{-1}$, as the 
Table 2: Comparison of the Measured Decay Coefficients and Current Densities in

Different Tunneling Junctions with $\mathrm{SAMs}$ of $\mathrm{SC}_{\mathrm{n}-1} \mathrm{CH}_{3}$.

\begin{tabular}{|c|c|c|c|c|c|c|}
\hline Type of junction & Top-electrode & $\begin{array}{l}\text { Bottom- } \\
\text { electrode }\end{array}$ & values of $n$ & $\begin{array}{l}J_{0} \\
\left(\mathrm{~A} / \mathbf{c m}^{2}\right)\end{array}$ & $\beta\left(\AA^{-1}\right)$ & ref \\
\hline $\begin{array}{l}\text { (1) } \mathrm{Au}- \\
\mathrm{SAM} / / \text { polymer} / \mathrm{Au}^{\mathrm{a}}\end{array}$ & $\begin{array}{l}\text { Conductive } \\
\text { polymer }\end{array}$ & $\mathrm{AS}-\mathrm{DEP}^{\mathrm{g}}$ & $8,10,12,14$ & $\sim 10^{5} \mathrm{~h}$ & $0.47 \pm 0.1$ & 26 \\
\hline $\begin{array}{l}\text { (2) } \mathrm{Au}- \\
\mathrm{SAM} / / \text { polymer } / \mathrm{Hg}^{\mathrm{b}}\end{array}$ & $\begin{array}{l}\text { Conductive } \\
\text { polymer }\end{array}$ & AS-DEP ${ }^{g}$ & $\begin{array}{l}8,10,12 \\
14,16\end{array}$ & $\sim 10^{2} \mathrm{~h}$ & $0.90 \pm 0.03$ & 55 \\
\hline (3) $\mathrm{Hg}-\mathrm{SAM} / / \mathrm{Hg}^{\mathrm{c}}$ & Liquid metal & $\begin{array}{l}\text { Liquid } \\
\text { metal }\end{array}$ & $\begin{array}{l}9,10,11,12,1 \\
5,16,18\end{array}$ & $\sim 10^{6 \mathrm{~h}}$ & $0.85 \pm 0.06$ & 56 \\
\hline (4) Au-SAM//graphene & Graphene & AS-DEP & $8,12,16$ & $2 \times 10^{8}$ & $0.84 \pm 0.1$ & 57 \\
\hline (5) Au-SAM-Au & $\begin{array}{l}\text { Direct } \\
\text { deposition of } \\
\mathrm{Au}\end{array}$ & AS-DEP & $8,12,16$ & $\sim 10^{8}$ & $0.80 \pm 0.03$ & 58 \\
\hline $\begin{array}{l}\text { (6) Ag- } \\
\mathrm{SAM} / / \mathrm{Ga}_{2} \mathrm{O}_{3} / \mathrm{EGaIn}\end{array}$ & $\begin{array}{l}\text { Liquid metal } \\
\text { (cross-bar) }\end{array}$ & TS & $\begin{array}{l}12,14,16 \\
18\end{array}$ & $\sim 340$ & $0.78 \pm 0.2$ & $\begin{array}{l}\text { 1, this } \\
\text { paper }\end{array}$ \\
\hline $\begin{array}{l}\text { (7a) Ag- } \\
\text { SAM } / / \mathrm{Ga}_{2} \mathrm{O}_{3} / \mathrm{EgaIn}^{\mathrm{d}, \mathrm{e}}\end{array}$ & $\begin{array}{l}\text { Liquid metal } \\
\text { (cone) }\end{array}$ & TS & $\begin{array}{l}10,12,14 \\
16,18\end{array}$ & $339 \pm 1$ & $0.792 \pm 0.01$ & 21 \\
\hline $\begin{array}{l}\text { (7b) } \mathrm{Ag}- \\
\mathrm{SAM} / / \mathrm{Ga}_{2} \mathrm{O}_{3} / \mathrm{EgaIn}^{\mathrm{d}, \mathrm{e}}\end{array}$ & $\begin{array}{l}\text { Liquid metal } \\
\text { (cone) }\end{array}$ & TS & $\begin{array}{l}9,11,13 \\
15,17\end{array}$ & $91 \pm 1$ & $0.819 \pm 0.01$ & 21 \\
\hline $\begin{array}{l}\text { (8) } \mathrm{Ag}- \\
\mathrm{SAM} / / \mathrm{Ga}_{2} \mathrm{O}_{3} / \mathrm{EgaIn}^{\mathrm{d}}\end{array}$ & $\begin{array}{l}\text { Liquid metal } \\
\text { (cone) }\end{array}$ & TS & $12,14,16$ & $(\sim 0.2)^{\mathrm{f}}$ & $(0.43 \pm 0.2)^{\mathrm{f}}$ & 19 \\
\hline $\begin{array}{l}\text { (9) } \mathrm{Ag}- \\
\mathrm{SAM} / / \mathrm{Ga}_{2} \mathrm{O}_{3} / \mathrm{EgaIn}^{\mathrm{d}, \mathrm{f}}\end{array}$ & $\begin{array}{l}\text { Liquid metal } \\
\text { (cone) }\end{array}$ & TS & $\begin{array}{l}10,12,14, \\
16\end{array}$ & $\sim 10^{3}$ & $0.88 \pm 0.2$ & 2,19 \\
\hline (10) Ag-SAM//SAM-Hg & Liquid metal & TS & $20,24,28$ & $\sim 10^{3}$ & 0.64 & 30 \\
\hline (11) $\mathrm{Si} / \mathrm{SiO}_{2} / / \mathrm{SAM}-\mathrm{Hg}$ & Liquid metal & $\mathrm{Si} / \mathrm{SiO}_{2}$ & $10,12,14,18$ & NA & 0.82 & 59 \\
\hline (12) $\mathrm{Si}-\mathrm{SAM} / / \mathrm{Hg}$ & Liquid metal & $\mathrm{Si}$ & $12,14,16,18$ & $1.5 \times 10^{4} \mathrm{~h}$ & 0.78 & 60 \\
\hline (13) $\mathrm{Hg}-\mathrm{SAM} / / \mathrm{SAM}-\mathrm{Hg}$ & Liquid metal & $\begin{array}{l}\text { Liquid } \\
\text { metal }\end{array}$ & $\begin{array}{l}18,20,22,24, \\
28\end{array}$ & $\sim 10^{2} \mathrm{~h}$ & 0.71 & 48 \\
\hline (14) Ag-SAM//SAM-Hg & Liquid metal & AS-DEP ${ }^{g}$ & $\begin{array}{l}24,26,28,30, \\
32\end{array}$ & $4 \times 10^{5}$ & 0.86 & 54 \\
\hline
\end{tabular}

${ }^{\mathrm{a}}$ The conductive polymer is PDOT:PSS with additives.

${ }^{\mathrm{b}}$ The conductive polymer is PmPV.

${ }^{\mathrm{c}}$ Slowinski et al. measured single SAMs instead of bilayers under electrochemical control.

${ }^{d}$ These junctions were assembled using conically shaped tips of $\mathrm{Ga}_{2} \mathrm{O}_{3} / E G a I n$ suspended from a syringe.

e Junctions with an even number of carbons gave larger values of $J$ than those junctions with an odd number of carbons. The values of $J_{0}$ and $\beta$ for the odd- and even-series were not statistically

distinguishable; this statistical uncertainty in these values make it impossible to conclude if the values are the same or different.

${ }^{\mathrm{f}}$ The analysis of the data reported in reference 19 was erroneous: this analysis was biased and was based on a data selection. See text for details.

${ }^{\mathrm{g}}$ AS-DEP indicates electrodes that were used as-deposited; TS indicates template-stripped electrodes from a $\mathrm{Si} / \mathrm{SiO}_{2}$ wafer; the values for $J_{0}$.

${ }^{\mathrm{h}}$ Roughly estimated from extrapolation of the plots $J$ vs carbon number reported in the corresponding references at $0.50 \mathrm{~V}$. 
Figure 5: The values of $\beta\left(\AA^{-1}\right)$ and $J_{0}$ (plotted on the same axes for ease of comparison) listed in Table 2 , along with histograms of $\beta$ and $J_{0}$. The black, dashed lines indicate the range of consensus values for $\beta$ and $J_{0}$. The plot has no theoretical basis: it is simply a method of displaying data that is convenient for identifying patterns. The numbers correspond to the numbered entries of Table 2. We do not know the value of $J_{0}$ for junction 11 and, hence, junction 11 could not be plotted in this graph. The data obtained by junctions with top-electrodes of cone-shaped tips $\mathrm{Ga}_{2} \mathrm{O}_{3} / \mathrm{EGaIn}$ are indicated with $\square$ and by top-electrodes of $\mathrm{Ga}_{2} \mathrm{O}_{3} / \mathrm{EGaIn}$ stabilized in microchannels with $\diamond$, all other data are indicated by $\bullet$. The red dashed line connects data for 8 and 9: these two data sets are the same but have been analyzed differently as discussed in the text. ${ }^{2}$ For the data labeled $7 \mathrm{a}$ and $7 \mathrm{~b}$, we found an oddeven effect: junctions with SAMs of n-alkanethiolates of an even number of carbons gave always larger values of $J$ than those junctions with an odd number of carbons. ${ }^{2}$ A detailed statistical analysis indicated with confidence levels of $>99 \%$ that the difference of the values of $J_{0}$ are significant $\left(p<10^{-13}\right)$, but the values of $\beta$ are statistically different but with a lower confidence level $(p=0.011) .{ }^{21}$ Data that are encircled with red are either suspect or incorrect, as explained in the text. 


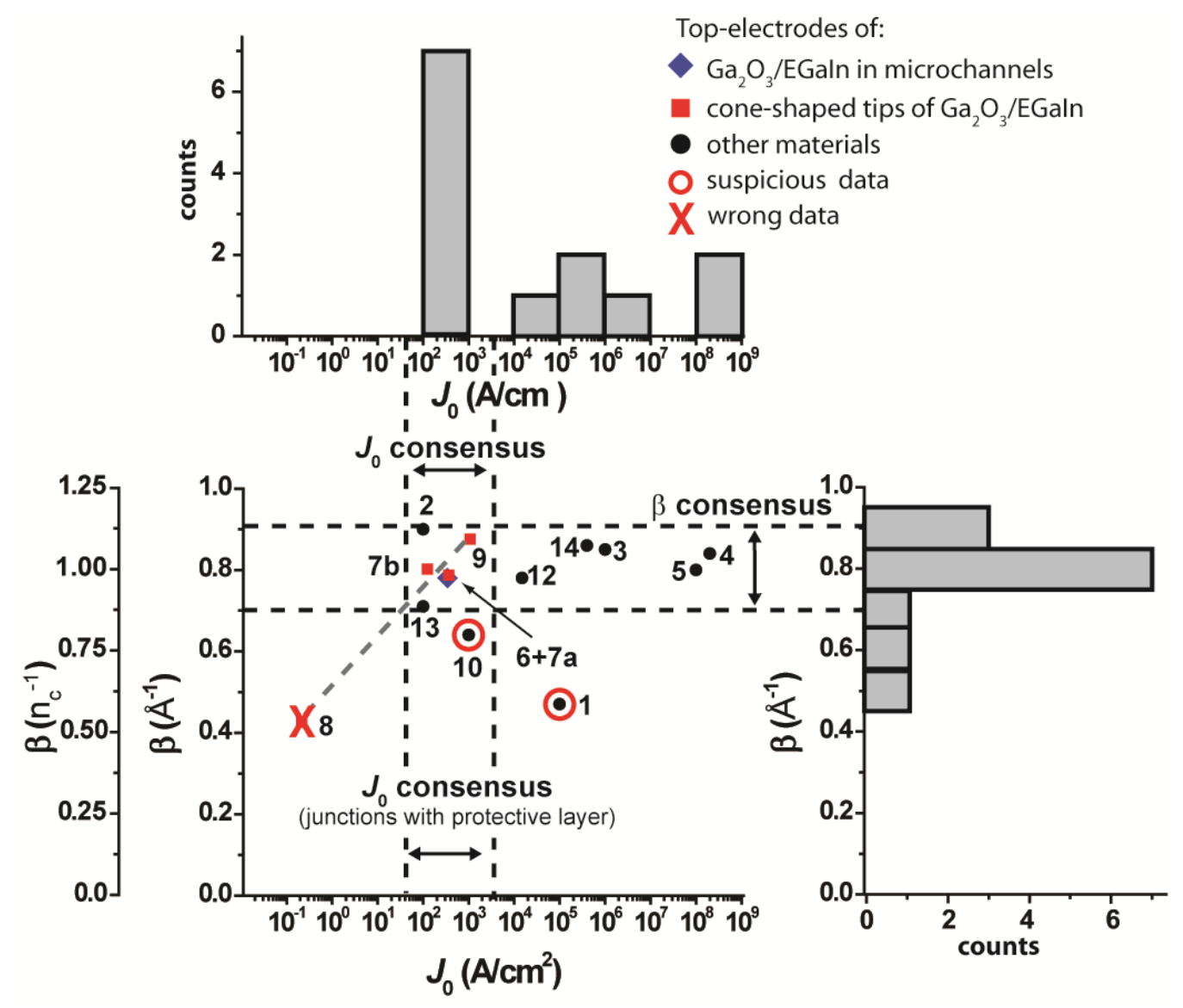


“consensus" value of $\beta$. Values of $J_{0}=10^{2}-10^{3} \mathrm{~A} / \mathrm{cm}^{2}$ may emerge as consensus values for this parameter for junctions in the same group having a protective layer, but at present this range should probably be considered as an empirical cluster of experimental data. There is presently no convincing theoretical justification for these values, and we consider them as hypotheses, against which to test future data and theory.

\section{Cone-Shaped Tips of $\mathrm{Ga}_{2} \mathrm{O}_{3} / \mathrm{EGaIn}$ vs $\mathrm{Ga}_{2} \mathrm{O}_{3} / \mathrm{EGaIn}$ Stabilized in}

Microchannels. In this section, we compare data obtained from junctions with topelectrodes of cone-shaped tips of $\mathrm{Ga}_{2} \mathrm{O}_{3} / \mathrm{EGaIn}$ with data obtained from junctions with top-electrodes of $\mathrm{Ga}_{2} \mathrm{O}_{3} / \mathrm{EGaIn}$ stabilized in microchannels. (In one prior publication the first communication describing the $\mathrm{Ga}_{2} \mathrm{O}_{3} / \mathrm{EGaIn}$ tip - we reported a low value of $\beta$ and $J_{0}$ for junctions of the type $\mathrm{Ag}^{\mathrm{TS}}-\mathrm{SAM} / / \mathrm{Ga}_{2} \mathrm{O}_{3} / \mathrm{EGaIn}$ with cone-shaped topelectrodes of $\mathrm{Ga}_{2} \mathrm{O}_{3} / \mathrm{EGaIn}: \beta=0.43 \AA^{-1}$, (or $\left.0.54 n_{\mathrm{C}}{ }^{-1}\right)$ and $J_{0}=0.2 \mathrm{~A} / \mathrm{cm}^{2}{ }^{2}$. These low values were based on an erroneous value for one n-alkanethiolate. We have corrected this early estimate in subsequent publications. ${ }^{2}$ )

SAM-based junctions with cone-shaped top-electrodes of $\mathrm{Ga}_{2} \mathrm{O}_{3} / \mathrm{EGaIn}$, and junctions with top-electrodes of $\mathrm{Ga}_{2} \mathrm{O}_{3} / \mathrm{EGaIn}$ stabilized in microchannels, have three differences that could lead to different experimental results. i) The contacting surfaces of cone-shaped top-electrodes of $\mathrm{Ga}_{2} \mathrm{O}_{3} / E G$ aIn are rough: they contain 1-2 $\mu$ m scale grains of $\mathrm{Ga}_{2} \mathrm{O}_{3} \cdot{ }^{20}$ Optical micrographs of the electrodes stabilized in microchannels show that they are smoother than the cone-shaped electrodes. ${ }^{1}$ We believe, therefore, that electrodes stabilized in microchannels conform better to the SAMs than cone-shaped tips, and have fewer regions of thick (and less conductive) $\mathrm{Ga}_{2} \mathrm{O}_{3}$ within the contact area, ii) Coneshaped top-electrodes of $\mathrm{Ga}_{2} \mathrm{O}_{3} / E G$ aIn formed in ambient conditions are covered (at 
least partially) with adventitious organic contaminants. ${ }^{20}$ Top-electrodes of $\mathrm{Ga}_{2} \mathrm{O}_{3} /$ EGaIn stabilized in microchannels were formed in a confined space under reduced pressure. As a result, we believe that these electrodes may have less adventitious material, or at least different adventitious material (e.g., low molecular weight siloxanes), on the surface than cone-shaped tips formed in ambient conditions. iii) Cone-shaped topelectrodes of $\mathrm{Ga}_{2} \mathrm{O}_{3} / E G$ aIn are covered with a continuous layer of $\mathrm{Ga}_{2} \mathrm{O}_{3}$, and, thus junctions formed with these electrodes are expected to have a continuous layer of $\mathrm{Ga}_{2} \mathrm{O}_{3}$ between the SAM and the bulk EGaIn. The layer of $\mathrm{Ga}_{2} \mathrm{O}_{3}$ covering top-electrodes of $\mathrm{Ga}_{2} \mathrm{O}_{3} / \mathrm{EGaIn}$ stabilized in microchannels appears to be discontinuous: these electrodes were formed in microchannels that lacked sufficient oxygen to react with all superficial Ga atoms as EGaIn flowed through the channel. These conditions apparently resulted in a discontinuous layer of $\mathrm{Ga}_{2} \mathrm{O}_{3}$ between the SAM and the bulk EGaIn. ${ }^{1}$

Figure 6 compares the values of $\langle\log (|J|)>$ obtained with these two different systems. It is surprising, given the apparent similarity of the two sets of data, that twosample Student's t-tests show that the differences between the values of $\langle\log (|J|)\rangle$ are statistically significant (for all $\mathrm{n}=12,14,16$, and 18). Even though the error bars overlap in all cases, the large numbers of data collected with each technique greatly increases the sensitivity of the t-tests. While the differences in the log-average values of $J$ are statistically significant, they are not consistent, i.e., the log-average values of $J$ determined with one method are not consistently larger than those values measured with the other method. Nonetheless we conclude that these (non-systematic) differences do not arise from factors intrinsic to the two methods. In fact, the two methods produce results that are surprisingly similar, given that they represent very distinct approaches to 
Figure 6: Comparison of $|J|$, at $V=-0.5 \mathrm{~V}$, measured using conical tips of $\mathrm{Ga}_{2} \mathrm{O}_{3} / \mathrm{EGaIn}$ (black squares; data taken from reference 2) and the microfluidic arrays (red circles; data taken from reference 1). For the former, values of $\mathrm{n}$ have been offset for clarity. 


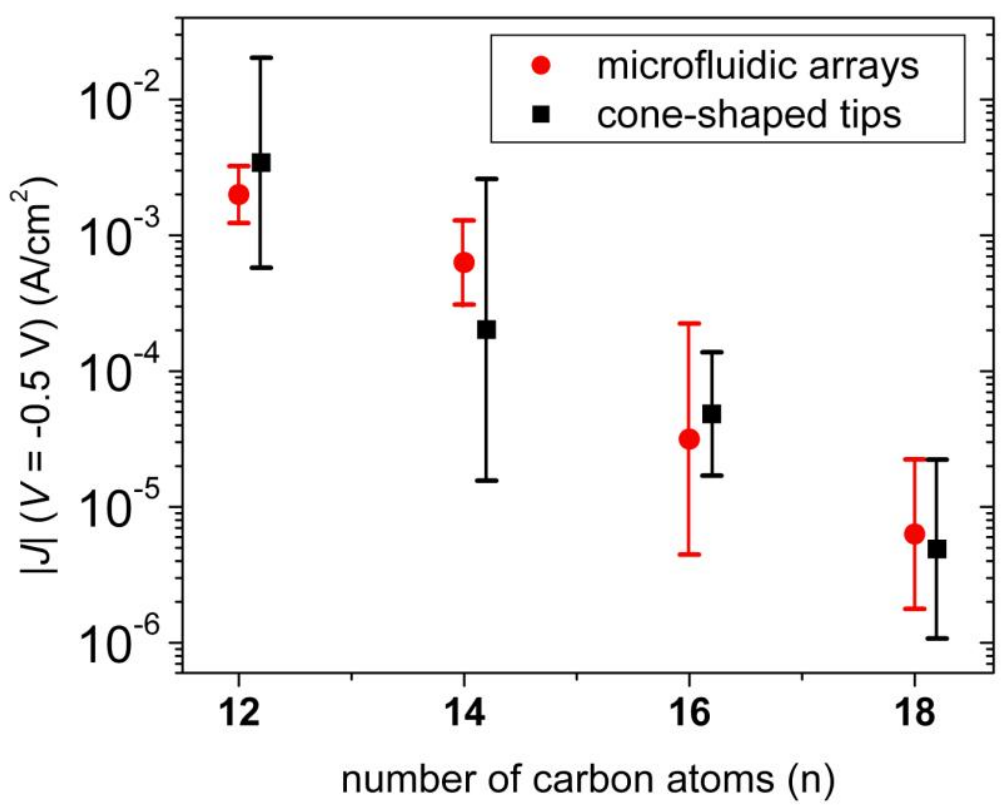


forming the contact between $\mathrm{Ga}_{2} \mathrm{O}_{3} / \mathrm{EGaIn}$ and the SAM. The similarity of these results implies that the properties of the $\mathrm{Ga}_{2} \mathrm{O}_{3}$ layer (with its adventitious organic material) either remain constant over a wide range of processing conditions, or do not affect measurements of charge transport through the types of SAMs studied so far, or both.

Junctions with Large Values of $\boldsymbol{J}_{\mathbf{0}}$. The substantial range of values for $\boldsymbol{J}_{0}$ suggest (not surprisingly, perhaps) that there may be different contributions to the resistance of junctions having different interfaces with the metallic conductors in the junction. These differences indicate that $J_{0}$ may emerge, with further study, as a more informative parameter with which to characterize these SAM-based junction than $\beta$.

The junctions described by Akkerman et al. have values of $J_{0}$ that are larger by a factor of $\sim 10^{2}$ than the values of $J_{0}$ we observe with the $\mathrm{Ga}_{2} \mathrm{O}_{3} / \mathrm{EGaIn}$-based systems; one interpretation of this result posits that the polymer intercalates with (or displaces) the SAM (see above), and reduces the width of the tunneling barrier in the junction. Another interpretation holds that the discrepancy in $J_{0}$ between these techniques reflects the different (area-scaled) resistances of the electrodes, and/or different efficiencies of charge injection at the interfaces between the respective electrodes and the SAM.

Lee et al. ${ }^{58}$ reported two values of $J_{0}$ (for Au-SAM-Au and $\mathrm{Au}-\mathrm{SAM} /$ /graphene/Au junctions) that are much larger than any other values (Table 2; Figure 9). The large value of $J_{0}$ for Au-SAM-Au junctions might indicate that the evaporated top-electrodes partially penetrated the SAMs, and resulted in a high density of thin-area defects. Thin-area defects will have a large affect on the measured values of $J$ (see background section), and will lead to higher values of $J$ than expected from the thickness of the SAMs and, thus, large values of $J_{0}$. Alternatively, the large values of $J_{0}$ 
may result from the fact that evaporated Au top-electrodes most likely form a very different contact with the SAM than $\mathrm{Hg}-\mathrm{SAM}$ or $\mathrm{Ga}_{2} \mathrm{O}_{3} / \mathrm{EGaIn}$ top-electrodes. Lee at al. ${ }^{57}$ also reported a very high value of $J_{0}$ (Table 2) for junctions in which a multilayer of graphene, rather than a conducting polymer, contacted the SAM and protected it during the deposition of the Au top-electrode material. The fact that $J_{0}$ for these graphene-based junctions are about a factor of $10^{5}$ larger than those values measured for junctions with $\mathrm{Ga}_{2} \mathrm{O}_{3} / \mathrm{EGaIn}$ electrodes may reflect the different interfaces formed by the SAM with a multi-layer of graphene and with a $\mathrm{Ga}_{2} \mathrm{O}_{3} / \mathrm{EGaIn}$ top-electrode.

One study by Slowinski et al. ${ }^{56}$ investigated $\mathrm{Hg}$-based junctions under potentiostatic control; they reported stable junctions of the form $\mathrm{Hg}-\mathrm{SAM} / \mathrm{Hg}$. These junctions have a value of $J_{0}$ that are about two orders of magnitude larger than those values reported for junctions with $\mathrm{Hg}-\mathrm{SAM}$ or $\mathrm{Ga}_{2} \mathrm{O}_{3} / \mathrm{EGaIn}$ top-electrodes.

The values of $J_{0}$ for junctions with $\mathrm{Ga}_{2} \mathrm{O}_{3} / \mathrm{EGaIn}$ top-electrodes are consistent with one another (within roughly one order of magnitude) and also with the values reported for junctions based on top-electrodes of $\mathrm{Hg}$-SAM. The values of $J_{0}$ for junctions of the form metal-SAM//metal are two to six orders of magnitude larger than for junctions of the form metal-SAM//SAM-metal or metal-SAM//Ga $\mathrm{O}_{3} /$ metal.

Junctions with Low Values of $\boldsymbol{\beta}$. Three papers report junctions giving values for $\beta$ that are lower than the consensus value: junctions with SAMs of n-alkanethiolates incorporating i) cone-shaped top-electrodes of $\mathrm{Ga}_{2} \mathrm{O}_{3} / \mathrm{EGaIn}$ and template-stripped silver bottom-electrodes (one of four values reported for $\mathrm{Ag}^{\mathrm{TS}}$-SAM//Ga $\mathrm{O}_{3} / \mathrm{EGaIn}$ junctions; point 8), ${ }^{19}$ ii) $\mathrm{Hg}$ drop top-electrodes and template-stripped silver bottom-electrodes $\left(\mathrm{Ag}^{\mathrm{TS}}\right.$-SAM//SAM-Hg; point 10$),{ }^{30}$ and iii) top-electrodes of PEDPOT:PSS with gold 
bottom-electrodes (Au-SAM//PEDOT:PSS-Au; point 1$).{ }^{26} \mathrm{We}$ have already indicated that the low value of $\beta$ for the first communication describing the cone-shaped topelectrodes of $\mathrm{Ga}_{2} \mathrm{O}_{3} / \mathrm{EGaIn}$ includes one erroneous datum, and is thus also incorrect ${ }^{2}$

The low values of $\beta$ reported for Au-SAM//PEDOT:PSS/Au might indicate that increasing the molecular length of the SAM does not equally increase the width of the tunneling barrier in these junctions, or that the mechanism of charge transport differs from ideal through-bond tunneling. Either of these phenomena could result from a significant modification, or even partial removal, of the SAM by the procedure used to apply the layer of PEDOT:PSS. ${ }^{26}$ This interpretation would also explain the long-term stabilities of the Akkerman-type of devices $\left(t_{1 / 2}>2.5\right.$ years $\left.{ }^{61}\right)$ despite the fact that the gold-thiolate bonds are only stable on the order of days in contact with $\mathrm{O}_{2} \cdot{ }^{55,62}$ while the PDOT:PSS is permeable for $\mathrm{O}_{2}{ }^{63,64}$

The results of the current work stand in contrast with a study ${ }^{30}$ comparing junctions of the form $\mathrm{Ag}^{\mathrm{TS}}-\mathrm{SC}_{\mathrm{n}-1} \mathrm{CH}_{3} / / \mathrm{CH}_{3} \mathrm{C}_{\mathrm{n}-1} \mathrm{~S}-\mathrm{Hg}$ and $\mathrm{Ag}^{\mathrm{AS}-\mathrm{DEP}}-\mathrm{SC}_{\mathrm{n}} / / \mathrm{C}_{\mathrm{n}} \mathrm{S}-\mathrm{Hg}$ (ASDEP means bottom-electrodes used "as-deposited" by e-beam evaporation; see Supplemental Information). This study indicated that $\mathrm{Ag}^{\mathrm{TS}}$ bottom-electrodes resulted in lower values of $\beta$ than $\mathrm{Ag}^{\mathrm{AS}-\mathrm{DEP}}$ bottom-electrodes (Table 2) because the $\mathrm{Ag}^{\mathrm{TS}}$ surfaces have a lower density of defects than SAMs on $\mathrm{Ag}^{\mathrm{AS}-\mathrm{DEP}}$ surfaces. These defects, in turn, affect the quality of shorter SAMs more than the longer ones, and lead to different values of $\beta$ for these two systems. This conclusion, however, differs from the results described in this paper. Here we report a value of $\beta$ for $\mathrm{Ag}^{\mathrm{TS}}$ bottom-electrodes $\left(0.98 \pm 0.2 n_{\mathrm{C}}{ }^{-1}\right.$, $\left.0.78 \pm 0.2 \AA^{-1}\right)$ that is higher than the previous value for $\mathrm{Ag}^{\mathrm{TS}}$ bottom-electrodes $\left(0.80 n_{\mathrm{C}}{ }^{-}\right.$ ${ }^{1}, 0.64 \AA^{-1}$ ), but approximately equal to the value obtained for $\mathrm{Ag}^{\mathrm{AS}-\mathrm{DEP}}$ bottom-electrodes 
$\left(1.1 n_{\mathrm{C}}^{-1}, 0.87 \AA^{-1}\right)$. We note that the previous study using $\mathrm{Ag}^{\mathrm{TS}}$ bottom-electrodes calculated a value of $\beta$ from the slope of a linear fit using only three $n$-alkanethiolates, which is not a large enough dataset to estimate the slope of a regression line with high statistical confidence. By contrast, the prior study using $\mathrm{Ag}^{\mathrm{AS}-\mathrm{DEP}}$ bottom-electrodes performed a linear regression on data from five n-alkanethiolates to determine $\beta$, and the current study employs four n-alkanethiolates. Another study, ${ }^{19}$ using $\mathrm{Ag}^{\mathrm{TS}}$ electrodes and conical tips of $\mathrm{Ga}_{2} \mathrm{O}_{3} / \mathrm{EGaIn}$, corroborates the value of $\beta$ found in this work (Table 2;

Figure 5). We conclude, therefore, that the previously observed difference in the values of $\beta$ between $\mathrm{Ag}^{\text {TS }}$ and $\mathrm{Ag}^{\mathrm{AS}-\mathrm{DEP}}$ bottom-electrodes probably reflects the uncertainty arising from a small dataset, and that we should consider the low value of $\beta$ represented by point 10 in Figure 5 to be anomalous. Furthermore, because reliable estimates of the values of $\beta$ for $\mathrm{Ag}^{\mathrm{TS}}$ and $\mathrm{Ag}^{\mathrm{AS}-\mathrm{DEP}}$ bottom-electrodes are roughly equivalent, we conclude that decreasing the density of defects in the SAM does not significantly affect $\beta$ (although doing so does increase the yield of non-shorting junctions, and may decrease the width of distributions of $J$ ).

\section{Conclusions}

Junctions with $\mathrm{Ga}_{2} \mathrm{O}_{3}$ /EGaIn stabilized in microchannels and junctions with cone-shaped tips of $\mathrm{Ga}_{2} \mathrm{O}_{3} / \mathbf{E G a I n}$ give similar values of $\boldsymbol{\beta}$ and $\boldsymbol{J}_{0}$. This paper demonstrates that using EGaIn (with a partial or complete $\mathrm{Ga}_{2} \mathrm{O}_{3}$ interface) topelectrodes, mechanically stabilized in microfluidic channels, for the fabrication of arrays of metal-SAM// $\mathrm{Ga}_{2} \mathrm{O}_{3} / \mathrm{EGaIn}$ junctions provides a useful method of measuring charge transport across SAM. Importantly, using $\mathrm{Ga}_{2} \mathrm{O}_{3} / \mathrm{EGaIn}$ suspended from a syringe gives 
$J(\mathrm{~V})$ data with statistically indistinguishable characteristics. Both methods are appropriate for physical-organic studies of charge transport, and both generate statistically large numbers of data. The area of the cross-bar junctions $\left(300 \mu \mathrm{m}^{2}\right)$ is well defined by the dimensions of the bottom-electrode and the microfluidic channel. The main difference between the two methods is the confinement of $\mathrm{Ga}_{2} \mathrm{O}_{3} / \mathrm{EGaIn}$ inside the microchannels, and its adhesion (mediated by the layer of gallium oxides) to the oxidized interior surface of the PDMS; this confinement provides the mechanical stability that is necessary for handling junctions in the laboratory. It also enables measurements of $J(\mathrm{~V})$ as a function of temperature; these temperature-dependent measurements are not possible with the cone-shaped tip of $\mathrm{Ga}_{2} \mathrm{O}_{3} / \mathrm{EGaIn}$ suspended from a syringe.

This fabrication of junctions using $\mathrm{Ga}_{2} \mathrm{O}_{3} / \mathrm{EGaIn}$ in microchannels differs from the method based on cone-shaped tips of $\mathrm{Ga}_{2} \mathrm{O}_{3} / \mathrm{EGaIn}$ suspended from a syringe in three ways. i) The composition and thickness of the layer of $\mathrm{Ga}_{2} \mathrm{O}_{3}$ in each type of junction is almost certainly different. The cone-shaped tips of $\mathrm{Ga}_{2} \mathrm{O}_{3} / \mathrm{EGaIn}$ were formed in ambient conditions, and subsequently brought into contact with the SAM. This method produces junctions with a continuous layer of $\mathrm{Ga}_{2} \mathrm{O}_{3}$ between the SAM and bulk EGaIn. By contrast, the $\mathrm{Ga}_{2} \mathrm{O}_{3} / \mathrm{EGaIn}$ top-electrodes in the microchannels were formed under reduced pressure ( 500 Torr). Under these conditions the microchannels probably did not contain sufficient $\mathrm{O}_{2}$ to react with all newly exposed $\mathrm{Ga}$ atoms during filling. ${ }^{1}$ This method most likely generated junctions with a thin or even discontinuous layer of $\mathrm{Ga}_{2} \mathrm{O}_{3}$ between the SAM and the bulk EGaIn. ${ }^{1}$ ii) To form the cone-shaped tips and to contact the SAMs with these tips, the $\mathrm{Ga}_{2} \mathrm{O}_{3} / \mathrm{EGaIn}$ tips had to be deformed in a way that resulted in ripples that were visible at high optical magnification. ${ }^{1}$ These deformations most likely 
cause (small) variations in the composition of the layer of $\mathrm{Ga}_{2} \mathrm{O}_{3}$ and in its thickness, and certainly caused the true contact area to deviate from that calculated on the basis of the footprint. $^{1,20}$ iii) We found by ToF SIMs and XPS that a (discontinuous) layer of organic contaminations covers the cone-shaped tips of $\mathrm{Ga}_{2} \mathrm{O}_{3} / \mathrm{EGaIn}$ formed under ambient conditions. ${ }^{20}$ The $\mathrm{Ga}_{2} \mathrm{O}_{3} / \mathrm{EGaIn}$ electrodes formed under reduced pressure (500 Torr) in the microchannels are probably covered with less, and perhaps different, adventitious material (including low molecular weight dimethylsiloxanes) than the cone-shaped $\mathrm{Ga}_{2} \mathrm{O}_{3} /$ EGaIn electrodes.

We emphasize that this problem of organic contamination of the surface of our electrode is, in principle, an issue with any electrode (including surfaces in junctions using evaporated gold, and break junctions) that has a high excess of surface energy (e.g., bare metals and oxides). Electrodes such as Hg-SAM - with low surface energy - are less likely to be influenced by adventitious adsorbates, although the presence of solvent complicates understanding the nature of interfaces in these junctions.

Despite their differences, both methods involving $\mathrm{Ga}_{2} \mathrm{O}_{3} / \mathrm{EGaIn}$ top-electrodes produce very similar values of $\beta$ and $J_{0}$. Thus, we conclude that the layer of $\mathrm{Ga}_{2} \mathrm{O}_{3}$ and the layer of organic contaminations adsorbed on its surface in these junctions do not significantly impact the measurements of $J(\mathrm{~V})$. This conclusion - that the measurements of $J(\mathrm{~V})$ are dominated by the chemical structure of the molecules, the supramolecular structure of the SAMs, and the nature of the interfaces inside the $\mathrm{Ag}^{\mathrm{TS}}$-SAM// $\mathrm{Ga}_{2} \mathrm{O}_{3} / \mathrm{EGaIn}$ junctions, rather than by the $\mathrm{Ga}_{2} \mathrm{O}_{3}$ film (which will be different for cross-bar and cone-shaped electrodes) - is one of the most important inferences from this work. 


\section{Junctions with $\mathrm{Ga}_{2} \mathrm{O}_{3} /$ EGaIn stabilized in Microchannels Have Advantages}

and Disadvantages Over Other Methods. Junctions formed with top-electrodes of $\mathrm{Hg}$ SAM and $\mathrm{Ga}_{2} \mathrm{O}_{3} / E G a I n$ give values for $\beta$ and $J_{0}$ that are similar to each other and lie within the consensus of other techniques (see Table 2 and Figure 5). Thus, both methods seem to produce good-quality junctions and reliable data, but top-electrodes of $\mathrm{Ga}_{2} \mathrm{O}_{3} /$ EGaIn have four advantages over junctions formed with top-electrodes of $\mathrm{Hg}$. i) $\mathrm{Ga}_{2} \mathrm{O}_{3} /$ EGaIn based junctions give better yields in working devices ( 80-100\%) than $\mathrm{Hg}$ based junctions $(\sim 25 \%) .{ }^{65}$ ii) unlike $\mathrm{Hg}, \mathrm{Ga}_{2} \mathrm{O}_{3} / \mathrm{EGaIn}$ is non-volatile, non-toxic, and does not alloy with the $\mathrm{Ag}$ bottom-electrode. iii) $\mathrm{Ag}^{\mathrm{TS}}-\mathrm{SAM} / / \mathrm{Ga}_{2} \mathrm{O}_{3} / \mathrm{EGaIn}$ junctions are stable for at least two to three days, although a small decrease in the current density is observed over this period (junctions using Hg top-electrodes are stable for 100-200 s). iv) $\mathrm{Ga}_{2} \mathrm{O}_{3} /$ EGaIn cannot intercalate with the SAM, as may the alkyl chains of a second SAM on $\mathrm{Hg}$ (or a polymer).

Akkerman et al. ${ }^{26}$ reported a method for fabricating SAM-based tunneling junctions of the type Au-SAM//polymer/Au. These junctions are reported to be stable for years, have excellent mechanical stability, and produce yields of nearly $100 \% .{ }^{61}$ Despite these excellent properties, we favor top-electrodes of $\mathrm{Ga}_{2} \mathrm{O}_{3} / \mathrm{EGaIn}$ over conducting polymers for physical-organic studies because the data obtained from the Akkerman system can be interpreted to suggest that during the fabrication of the devices the polymer may intercalate into the SAM, and alter or even displace it. A process that changes the nature of the SAM will influence the mechanism of charge transport, and hamper the interpretation of data of physical-organic studies generated by junctions using polymers as top-electrodes. Also, unlike polymer-based systems, $\mathrm{Ga}_{2} \mathrm{O}_{3} / \mathrm{EGaIn}$ is probably 
compatible with many different types of SAMs. The very interesting junction reported by McCreary et al., ${ }^{66}$ based on evaporated carbon top electrodes, has excellent stability, but published characterization is not presently sufficiently detailed to allow comparison with the systems discussed here.

The method we report here overcomes many, but not all, of the problems associated with the fabrication of SAM-based tunneling junctions, but it has three disadvantages. i) The $\mathrm{SAM} / / \mathrm{Ga}_{2} \mathrm{O}_{3}$ interface is still incompletely defined. We believe that the $\mathrm{Ga}_{2} \mathrm{O}_{3}$ forms a van der Waals interface with $\mathrm{CH}_{3}$-terminated SAMs. ii) Although, the electrical characteristics of the $\mathrm{Ga}_{2} \mathrm{O}_{3}$ layer do not seem to influence the junctions, the influence of the topography of the $\mathrm{Ga}_{2} \mathrm{O}_{3}$ layer on the characteristics of the junction is still undefined. iii) The stability of our devices (two to three days) is good enough for physical-organic studies, but for most practical applications (e.g., in devices) stabilities on the order of years are required.

Thus, our method seems to be suitable for physical-organic studies that compare relative values of $J$ rather than absolute values of $J$, despite incomplete understanding of the details of the contact between the $\mathrm{Ga}_{2} \mathrm{O}_{3} / \mathrm{EGaIn}$ and the SAM. This method still lacks, however, the stability required for widespread applications.

\section{$J(V)$ measurements as a function of temperature are required to determine}

the mechanism of charge transport. Junctions with $\mathrm{Ga}_{2} \mathrm{O}_{3} / \mathrm{EGaIn}$ stabilized in microchannels make it possible to conduct measurements of $J(\mathrm{~V})$ as a function of temperature over the range of $110-293 \mathrm{~K}$. Such measurements are required to confirm

the mechanism of charge transport. ${ }^{10,67,68,69}$ We found that the $J(\mathrm{~V})$ characteristics of junctions with $\mathrm{SAMs}$ of $\mathrm{SC}_{\mathrm{n}-1} \mathrm{CH}_{3}$ are, as expected, (roughly) independent of temperature 
over this range. Thus, tunneling is the dominant mechanism of charge transport across these junctions. For junctions with $\mathrm{SAMs}$ of $\mathrm{SC}_{17} \mathrm{CH}_{3}$, we found a small thermally activated component in the mechanism of charge transport, with an activation energy of $10 \pm 2.1 \mathrm{meV}$. We do not know the origin of this small contribution, but it might involve charge transport across the layer of $\mathrm{Ga}_{2} \mathrm{O}_{3}$, conformational changes of the molecules, or charge transport mediated by impurities. For junctions with $\mathrm{SAMs}$ of $\mathrm{SC}_{13} \mathrm{CH}_{3}$, the activation energy was not significantly different from zero.

\section{Values of $\beta$ and $J_{0}$ are both required to determine the quality of SAM-Based}

junctions. Our junctions give values of $\beta$ of $0.98 \pm 0.2 n_{\mathrm{C}^{-1}}\left(\right.$ or $\left.0.78 \pm 0.2 \AA^{-1}\right)-$ effectively identical to the consensus value of $1.0 n_{\mathrm{C}}^{-1}$ (or $0.80 \AA^{-1}$ ). While there is a consensus on $\beta$, a value of $\beta=0.70-0.90 \AA^{-1}$, or $0.875-1.125 n_{\mathrm{C}}^{-1}$, should not necessarily be regarded as an indication of a "high quality" tunneling junction without first evaluating $J_{0}$. For many systems, values of $\beta$ close to consensus value have been reported, but the spread of the values of $J_{0}$ among these systems spans more than eight orders of magnitude (Table 2 ; Figure 5). The fact that $\beta=0.70-0.90 \AA^{-1}$, or $0.875-$ $1.125 n_{\mathrm{C}}{ }^{-1}$, has been confirmed by many different techniques establishes it as a consensus value, but also suggests that the variations across these systems are not large enough to influence the value of $\beta$, unlike the value of $J_{0}$, which requires extrapolation of data over a large range and is, by definition, sensitive not only to the SAM, but also to interfaces, electrodes, and protective layers. Here we report a value of $J_{0}$ of $\sim 3.4 \times 10^{2} \mathrm{~A} / \mathrm{cm}^{2}$ for even-numbered n-alkanethiolates; this value is close to values reported for several similar systems (Table 2; Figure 5) of the form metal-SAM//(protective layer)liquid metal (protective layer is $\mathrm{Ga}_{2} \mathrm{O}_{3}$ for EGaIn, or a second $\mathrm{SAM}$ for $\mathrm{Hg}$ ). We believe that systems 
giving values of $J_{0}$ outside the range of $10^{2}-10^{3} \mathrm{~A} / \mathrm{cm}^{2}$ for these types of junctions (despite having the correct value of $\beta$ ), must be interpreted on a case-by-case basis. The factors that determine $J_{0}$ are complicated and not well-understood. For instance, junctions reported by Lee et al. with graphene as protective layer, ${ }^{57}$ or metal directly deposited on the SAMs,${ }^{58}$ generate values of $J_{0}$ that are in the range of $10^{8} \mathrm{~A} / \mathrm{cm}^{2}$. These high values may suggest that the top-electrodes in these systems interact with the SAM in a different way than $\mathrm{Ga}_{2} \mathrm{O}_{3} / \mathrm{EGaIn}$, or $\mathrm{Hg}$-SAM, top-electrodes, or that other phenomena (formation of filaments, or thin-area defects) are involved, or that there are unrecognized factors in the class of junctions with "protective layers" that increases their resistivity in ways for which we do not currently account. A complete understanding of these SAM-based tunneling junctions should be able to reconcile values of both $\beta$ and $J_{0}$ across the several classes of junctions that have been developed and examined.

\section{Acknowledgements}

C.A.N. acknowledges the Netherlands Organization for Scientific Research (NWO) for the Rubicon grant supporting this research and the Singapore National Research Foundation under NRF Award No. NRF-RF2010-03. This research was supported by the U.S. Department of Energy, Office of Basic Energy Sciences, Division of Materials Sciences and Engineering under Award \# DE-FG02-OOER45852 (cleanroom fabrication, measurements of $J(\mathrm{~V})$ and support for J.R.B.), and by the National Science Foundation under Award \# CHE-05180055 (measurements of charge transport and support for W.F.R.). 
Supplemental Information. The experimental procedures, nomenclature, and the $J(\mathrm{~V})$ characteristics of $\mathrm{a} \mathrm{Ag}^{\mathrm{TS}}-\mathrm{SC}_{11} \mathrm{CH}_{3} / / \mathrm{Ga}_{2} \mathrm{O}_{3} / \mathrm{EGaIn}$ junction that was stable during $J(\mathrm{~V})$ measurement for 13 days are included in supplemental information. This material is available free of charge via the Internet at http://pubs.acs.org.

\section{References}

${ }^{1}$ Nijhuis, C. A.; Reus, W. F.; Barber, J. R.; Dickey, M. D.; Whitesides, G. M. Nano Lett. 2010, 10, 3611-3619.

${ }^{2}$ Thuo, M. M.; Reus, W. F.; Nijhuis, C. A.; Barber, J. R.; Kim, C.; Schulz, M. D.;

Whitesides, G. M. J. Am. Chem. Soc. 2011, 133, 2962-2975.

${ }^{3}$ Akkerman, H. B.; de Boer, B. J. Phys.: Condens. Matter. 2008, 20, 013001-013003.

${ }^{4}$ Predel, B; Stein, D. W. J. Less-Common Met. 1969,18, 49.

${ }^{5}$ Wimbush, K. S.; Reus, W. F.; van der Wiel, W. G.; Reinhoudt, D. N.; Whitesides, G.

M.; Nijhuis, C. A.; Velders, A. H. Angew. Chem. Int. Ed. 2010, 49, 10176-10180.

${ }^{6}$ Ramachandra, S.; Schuermann, K. C.; Edafe, F.; Belser, P.; Nijhuis, C. A.; Reus, W. F.;

Whitesides, G. M.; De Cola, L. Inorganic Chemistry, 2011, 50, 1581-1591.

${ }^{7}$ Fracasso, D.; Valkenier, H.; Hummelen, J. C.; Solomon, G. C.; Chiechi, R. C. J. Am. Chem. Soc., 2011, 133, 9556-9563.

${ }^{8}$ Engelkes, V. B.; Beebe, J. M.; Frisbie, C. D. J. Am. Chem. Soc. 2004, 126, $14287-$ 14296.

${ }^{9}$ Lindsay, S. M.; Ratner, M. A. Adv. Mater. 2007, 19, 23-31.

${ }^{10}$ McCreery, R. L Chem. Mater. 2004, 16, 4477-4496. 
${ }^{11}$ Paddon-Row, M. N.; Shephard, M. J.; Jordan, K. D. J. Phys. Chem. 1993, 97, 17431745.

${ }^{12}$ Simmons, J. G. J. Appl. Phys. 1963, 34, 1793-1803.

${ }^{13}$ Simmons, J. G. J. Appl. Phys. 1963, 34, 2581-2590.

${ }^{14}$ McConnell, H. M. J. Chem. Phys. 1961, 35,508-515.

15 Joachim, C.; Ratner, M. A. Proc. Natl. Acad, Sci. USA 2005, 102, 8801-8808.

${ }^{16}$ Yoon, H. J.; Shapiro, N. D.; Park, K. M.; M. M.; Thuo, Soh, S.; Whitesides, G. M.; Angew. Chem., Int. Ed. in press.

${ }^{17}$ Nijhuis, C. A.; Reus, W. F.; Whitesides, J. Am. Chem. Soc. 2009, 131, 17814-17827.

${ }^{18}$ Nijhuis, C. A.; Reus, W. F.; Whitesides, J. Am. Chem. Soc. 2010, 132, 18386-18401.

${ }^{19}$ Chiechi, R. C.; Weiss, E. A.; Dickey, M. D.; Whitesides, G. M. Angew. Chem., Int. Ed. 2008, 47, 142-144.

${ }^{20}$ Cademartiri, L.; Thuo, M. N.; Nijhuis, C. A.; Reus, W. F.; Tricard, S.; Barber, J.;

Sodhi, R.; Brodersen, P.; Kim, C.; Chiechi, R.;Whitesides, G. M. J. J. Phys. Chem. C 2012, DOI: $10.1021 / j p 212501 s$.

${ }^{21}$ Reus, W. F.; Nijhuis, C. A.; Barber, J.; Thuo, M. N.; Tricard, S.; Whitesides, G. M. J. Phys. Chem. C 2012, 116, 6714-6733.

${ }^{22}$ Deng, J.; Hofbauer, W.; Chandrasekhar, N.; O’Shea, S. J. Nanotech. 2007, 18, 155202155205.

${ }^{23}$ Walker, A. V.; Tighe, T. B.; Cabarcos, O. M.; Reinard, M. D.; Haynie, B. C.; Uppili, S.; Winograd, N.; Allara, D. L. J. Am. Chem. Soc. 2004, 126, 3954-3963. 
${ }^{24}$ Fisher, G. L.; Walker, A. V.; Hooper, A. E.; Tighe,T. B.; Bahnck, K. B.; Skriba, H. T.;

Reinard, M. D.; Haynie, B. C.; Opila, R. L.; Winograd, N.; Allara, D. L. J. Am. Chem.

Soc. 2002, 124, 5528-5541.

${ }^{25}$ Rampi, M. A.; Whitesides, G. M. Chemical Physics 2002, 281, 373-391.

${ }^{26}$ Akkerman, H. B.; Blom, P. W. M.; de Leeuw, D. M.; de Boer, B. Nature 2006, 440, 69-72.

${ }^{27}$ Regan, M. J.; Tostmann, H.; Pershan, P. S.; Magnussen, O. M.; DiMasi, E.; Ocko, B. M.; Deutsch, M. Phys. Rev. B: Condens. Matter 1997, 55, 10786-10792.

${ }^{28}$ Tostmann, H.; DiMasi, E.; Ocko, B. M.; Deutsch, M.; Pershan, P. S. J. Non-Cryst. Sol. 1999, $182250-252$.

${ }^{29}$ Paterson, G. W.; Wilson, J. A.; Moran, D.; Hill, R.; Long, A. R.; Thayne, I.; Passlack, M.; Droopad, R. Mater. Sci. Eng. B, 2006, 135, 277-281.

${ }^{30}$ Weiss, E. A.; Chiechi, R. C.; Kaufman, G. K.; Kriebel, J. K.; Li, Z.; Duati, M.; Rampi, M. A.; Whitesides G. M. J. Am. Chem. Soc. 2007, 129, 4336-4349.

${ }^{31}$ Love, J. C.; Estroff, L. A.; Kriebel, J. K.; Nuzzo, R. G.; Whitesides, G. M. Chem. Rev. 2005, 105, 1103-1169.

${ }^{32}$ Poirier, G. E. Chem. Rev. 1997, 97, 1117-1128.

${ }^{33}$ Love, J. C.; Wolfe, D. B.; Haasch, R.; Chabinyc, M. L.; Paul, K. E.; Whitesides, G. M.;

Nuzzo, R. G. J. Am. Chem. Soc. 2003, 125, 2597-2609.

${ }^{34}$ Aizenberg, J.; Black, A. J.; Whitesides, G. M. Nature 1999, 398, 495-498.

${ }^{35}$ Dickey, M. D.; Chiechi, R. C.; Larson, R. J.; Weiss, E. A.; Weitz, D. A.; Whitesides, G. M. Adv. Funct. Mater. 2008, 18, 1097-1104. 
${ }^{36}$ Larsen, R. J.; Dickey, M. D.; Whitesides, G. M.; Weitz, D. A. J. Rheol. 2009, 53, 1305-1326.

${ }^{37}$ Lee, S. -Y.; Tung, H. -W.; Chen, W. -C.; Fang, W. IEEE Photon. Technol. Lett. 2006, 18, 2191-2193.

${ }^{38}$ Menke, Y.; Peltier-Baron, V.; Hampshire, S. J. Non-Cryst. Solids 2000, 276, 145-150.

${ }^{39}$ Yamaga, M.; Víllora, E.G.; Shimamura, K.; Ichinose, N.; Honda, M.; Phys. Rev. B 2003, 68, 155207-155215.

${ }^{40}$ Lide, D. R. Handbook of Chemistry and Physics CRC Press, Inc.: Boca Raton, 1996.

${ }^{41}$ Koster, J. N. Cryst. Res. Technol. 1999, 34, 275-283.

${ }^{42}$ Laibinis, P. E.; Whitesides, G. M.; Allara, D. L.; Tao, Y. T.; Parikh, A. N.; Nuzzo, R. G. J. Am. Chem. Soc. 1991, 113, 7152-7167.

${ }^{43}$ Galperin, M.; Ratner, M. A.; Nitzan, A. J. Chem. Phys. 2004, 121, 11965-11979.

${ }^{44}$ Martín, S.; Giustiniano, F.; Haiss, W.; Higgins, S. J.; Whitby, R. J.; Nichols, R. J. J. Phys. Chem. C 2009, 113, 18884-18890.

${ }^{45}$ Wang, W.; Lee T.; Reed, M. A Rep. Prog. Phys. 2005, 68, 523-544.

${ }^{46}$ Salomon, A.; Cahen, D.; Lindsay, S.; Tomfohr, J.; Engelkes, V. B.; Frisbie, D. C. Adv. Mater. 2003, 15, 1881-1890.

${ }^{47}$ Cui, X. D.; Zarate, X.; Tomfoh1, J.; Sankey, O. F.; Primak, A.; Moore, A. L.; Moore, T. A.; Gust, D.; Harris, G.; Lindsay, S. M. Nanotechnology 2002, 13, 5-14.

${ }^{48}$ Slowinski, K.; Fong, H. K. Y.; Majda, M. J. Am. Chem. Soc. 1999, 121, 7257-7261.

${ }^{49}$ Beebe, J. M.; Engelkes, V. B.; Miller, L. L.; Frisbie, C. D. J. Am. Chem. Soc. 2002, $124,11268-11269$. 
${ }^{50}$ Wold, D. J.; Haag, R.; Rampi, M. A.; Frisbie, C. D. J. Phys. Chem. C. 2002, 106, 2813-2816.

${ }^{51}$ Xu, B. Q.; Tao, N. J. J. Science, 2003, 301, 1221-1223.

${ }^{52}$ Venkataraman, L.; Klare, J. E; Tam, I. W.; Nuckolls, C.; Hybertsen, M. S.; and Steigerwald, M. L. Nano Lett. 2004, 6,458-462.

${ }^{53}$ Li, X. L. ; He, J.; Hihath, J.; Xu, B. Q.; Lindsay, S. M.; Tao, N. J. J. Am. Chem. Soc. 2006, 128, 2135-2141.

${ }^{54}$ Holmlin, R. E.; Haag, R.; Chabinyc, M. L.; Ismagilov, R. F.; Cohen, A. E.; Terfort, A.; Rampi, M. A.; Whitesides, G. M. J. Am. Chem. Soc. 2001, 123, 5075-5085.

${ }^{55}$ Milani, F.; Grave, C.; Ferri, V.; Samon, P. ; Rampi, M. A. ChemPhysChem 2007, 8, $515-518$

${ }^{56}$ York, R. L.; Nguyen, P. T.; Slowinski, K. J. Am. Chem. Soc. 2003, 125, 5948-5953.

${ }^{57}$ Wang, G.; Kim Y.; Choe, M.; Kim, T.-W.; Lee, T. Adv. Mater. Adv. Mater. 2011, 23, $755-760$.

${ }^{58}$ Kim, T. W.; Wang, G.; Lee, H.; Lee, T. Nanotechnology 2007, 18, 315204-315211.

${ }^{59}$ Selzer, Y.; Salomon, A.; Cahen, D. J. Am. Chem. Soc. 2002, 124, 2886-2887.

${ }^{60}$ Salomon, A.; Boecking, T.; Seitz, O.; Markus, T.; Amy, F.; Chan, C.; Zhao, W.;

Cahen, D.; Kahn, A. Adv. Mater. 2007, 19, 445-450.

${ }^{61}$ Akkerman, H. B.; Kronemeijer, A. J.; Harkema, J.; van Hal, P. A.; Smits, E. C.P.; de Leeuw, D. M.; Blom, P. W.M. Org. Elec. 2010, 11, 146-149.

${ }^{62}$ Willey, T. M.; Vance, A. L.; van Buuren, T.; Bostedt, C.; Terminello, L. J.; Fadley, C. S. Surf. Sci. 2005,576, 188-196. 
${ }^{63}$ Andersen, M.; Carlé, J. E.; Cruys-Bagger, N.; Lilliedal, M. R.; Hammond, M. A.;

Winther-Jensen, B.; Krebs, F. C. Sol. Energy Mater. Sol. Cells 2008, 92, 686-714.

${ }^{64}$ Jørgensen, M.; Norrman, K.; Krebs, F. C. Sol. Energy Mater. Sol. Cells 2007, 91, 539543.

${ }^{65}$ Thuo, M. M.; Reus, W. F.; Kim, C.; Simone, F. C.; Schulz, M. D.; Yoon, H. J.; Whitesides, G. M. unpublished results.

${ }^{66}$ Yan, H.; Bergren, A. J.; McCreery, R. L. J. Am. Chem. Soc. 2011, 133, 19168-19177.

${ }^{67}$ Choi, S. H.; Kim, B.; Frisbie, C. D. Science 2008, 320, 1482-1486.

${ }^{68}$ Li, X. L.; Hihath, J.; Chen, F.; Masuda, T.; Zang. L.; Tao, N. J. J. Am. Chem. Soc. 2007, 129, 11535-11542.

${ }^{69}$ Xue, Y.; Ratner, M. A. Phys. Rev. B 2003, 68, 115406-115416. 
TOC figure:
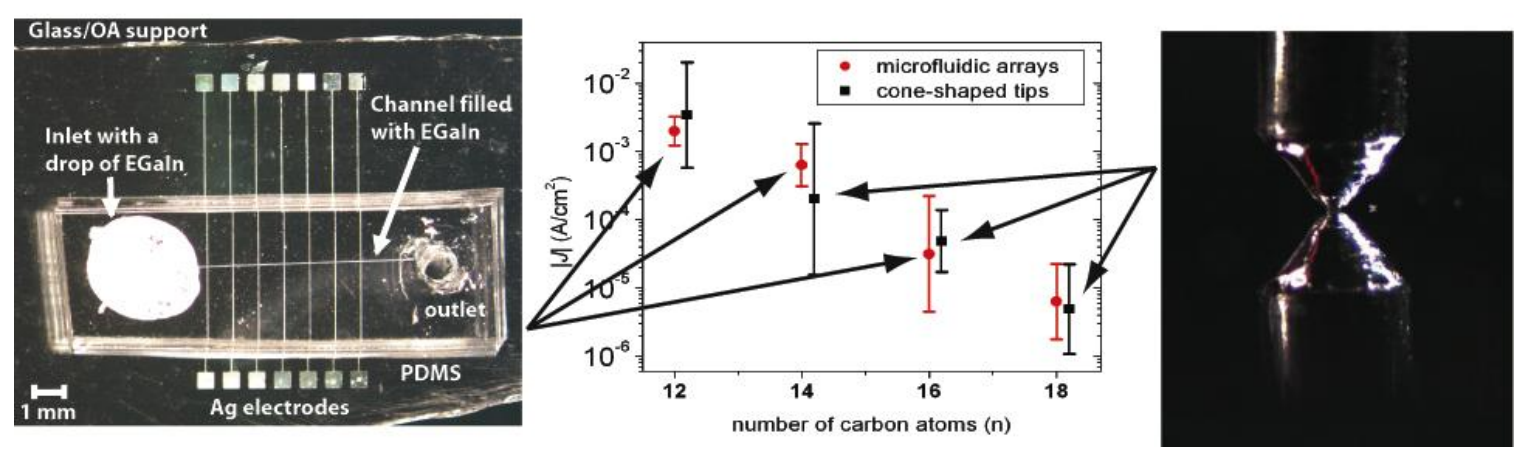